\title{
Boston Washer Study
}

\section{David J. Durfee \\ John J. Tomlinson}

\author{
Prepared by the \\ Energy Division \\ Oak Ridge National Laboratory \\ For the \\ U.S. Department of Energy \\ September 2001
}





\section{ACKNOWLEDGMENTS}

The authors would like to acknowledge Ms. Jennie Marino, Ms. Sylvia Greene, Mr. Joel Horn, Ms. Frances Tavares, Mr. William R. Wiggin, Ms. Vera Csikos, Mr. Stephen C. Saia, Mr. Fred L. Conover, Mr. \& Mrs. Daniel Baczkowski, Mr. Gaspare Bova, Mr. Roy Cheng, Mr. Russell Reed, Ms. Sandy Fermano, Ms. Margaret Jacobs, Ms. Carolyn M. Ritchie, Mr. Brian Jones-Kelly, Mr. Robert K. Pratt, Ms. Eileen Moynihan, Mr. Joseph Pagliccio, Mr. Richard Blank, Ms. Arlene Bazarion, Ms. Monica Widoff, Mr. Marvin A. Schuster, Mr. William M. Rowley, Ms. Margaret Fuller, Ms. Kerin Ann O'Donnell, Ms. Lillian Lipinski, Mr. Robert Ingraham, Ms. Deborah Palm, Mr. David Carnes, Mr. Thomas Bialaski, Mr. Angelo Liani, Ms. Jane Chisholm, Mr. Barry Levene, Mr. John E. Magazzu, Ms. Pamela Weigart, Mr. Norman F. Rolfe, Ms. Cheryl Johnson, Mr. Luis Zampitella, Mr. Frank Rosetti, Mr. \& Mrs. Richard Browne, Mr. Weldell Dwyer, Mr. Ray Gerke, Mr. Harold Reicker, Mr. Richard Bizzarro, Mr. Henry O. Marcy, Mr. Michael Pensavalli, Ms. Marsha Bloom, Mr. John Connolly, and Ms. Marilyn Morgan for their participantion in this study. Without their continious data gathering during the 5month study, this field study would not have been possible. Peg Fuller deserves special recognition; she was an important liaison between the project managers and the participants. We would also like to thank Mary Woomer at American Properties for her help setting up the study in Boston. We would also like to thank Boston Gas and the Northeast Energy Efficiency Partnerships Inc. for their support of this project.

The authors would also like to express gratitude to Maytag Appliances for providing the horizontal axis washers (Neptune models) and dryers for use in phase II of the study and for installing all of the equipment (washers, dryers and instrumentation) used in the study.

The authors would also like to thank Marc LaFrance and Jim Brodrick, Program Managers of the Advanced Appliance and Emerging Technologies Program under the U.S. Department of Energy for their help and support of this project.

Without the help and assistance of these organizations and individuals, the project would not have been possible. 



\section{Table of Contents}

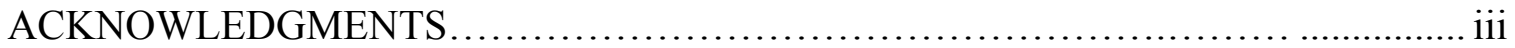

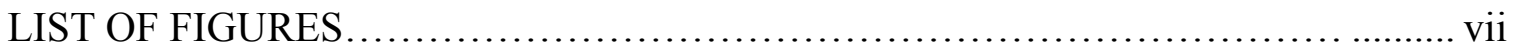

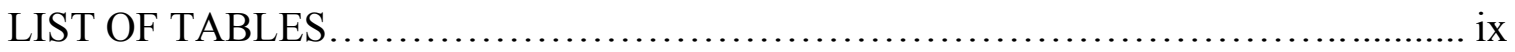

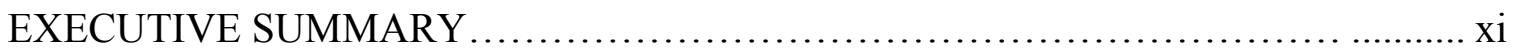

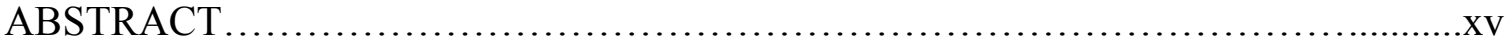

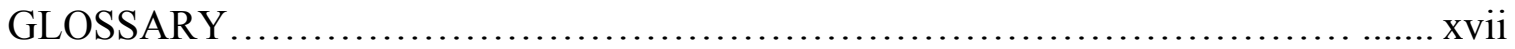

1. OVERVIEW AND OBJECTIVE OF THE FIELD STUDY ........................

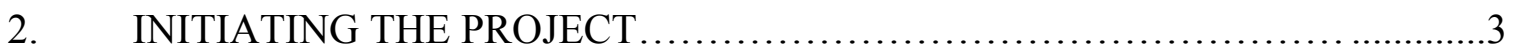

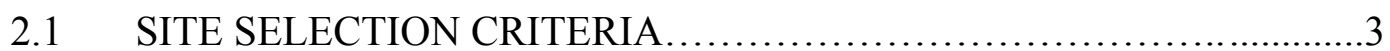

2.2 BOSTON LOCATION SELECTED FOR FIELD TEST ......................

2.3 BOSTON, MASSACHUSETTS ........................................4

2.4 PARTICIPANT SELECTION ............................................

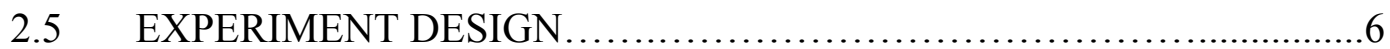

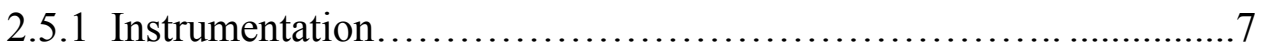

2.5.2 Schedule...................................................... 11

2.6 DATA COLLECTION AND ANALYSIS PROCEDURE .................12

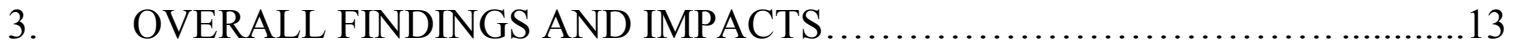

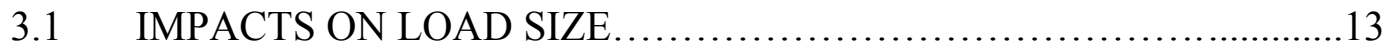

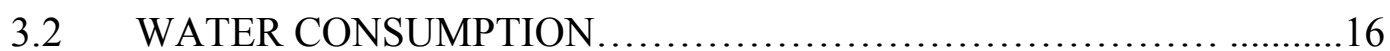

3.3 ENERGY CONSUMPTION........................................... 17

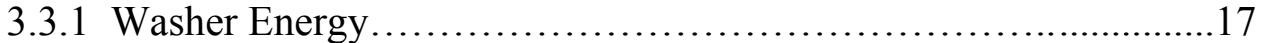

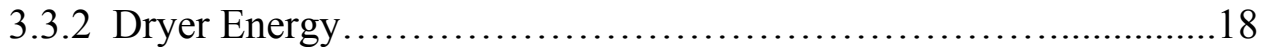

3.4 DETERGENT USE........................................................

3.5 IMPACTS ON LAUNDRY HABITS ....................................21

3.6 IMPACTS ON WASHER SETTINGS .................................... 22

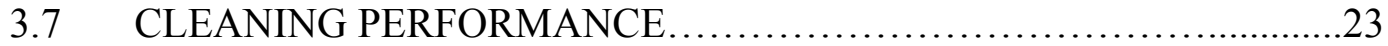

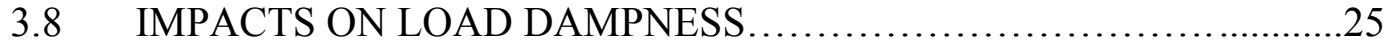

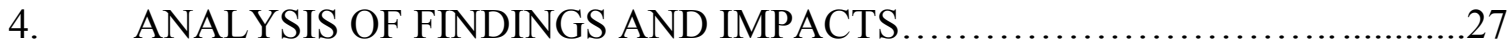

4.1 DRYER ENERGY SAVINGS ..............................................27

4.2 REMAINING MOISTURE CONTENT AND DRYER ENERGY USE..28

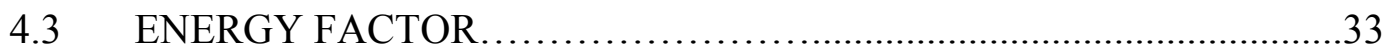

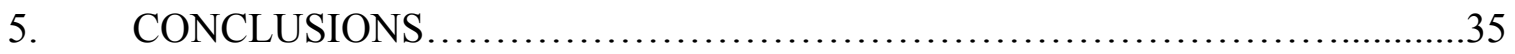

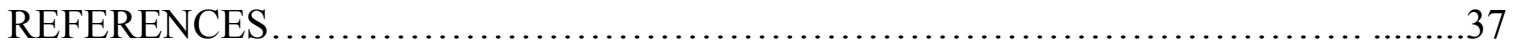

APPENDIX A. INSTRUMENTATION MODIFICATION ............................ 1

APPENDIX B. REPORTS TO RESIDENTS .......................................

APPENDIX C. INTEGRITY AND QUALITY OF DATA............................. 7

APPENDIX D. INDIVIDUAL WATER TAP TEMPERATURES .......................9 



\section{LIST OF FIGURES}

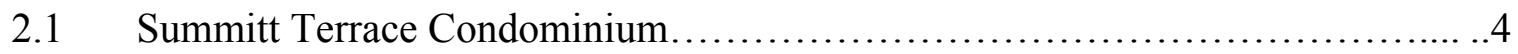

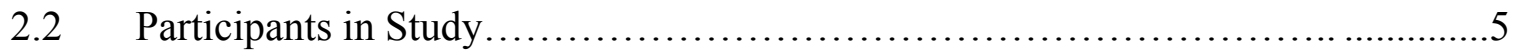

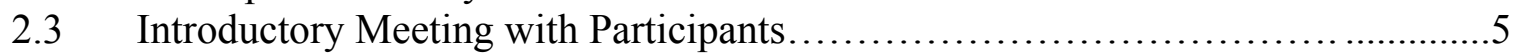

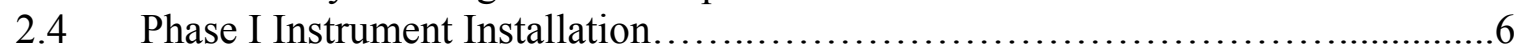

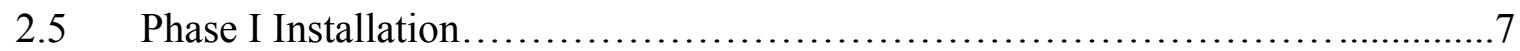

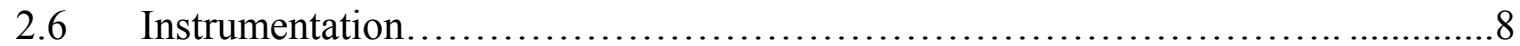

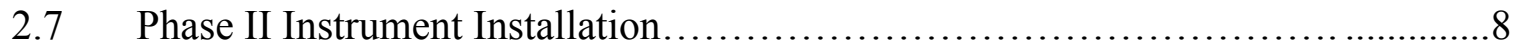

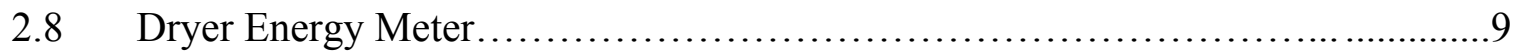

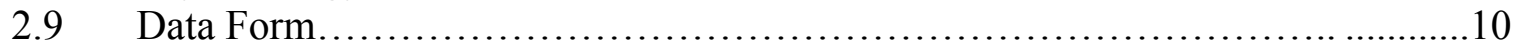

2.10 Phase II Machines with Instrumentation.........................................11

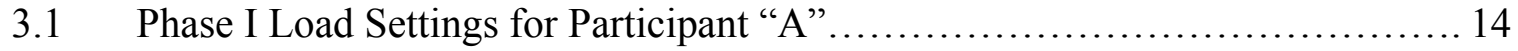

3.2 Phase I Load Settings for Participant "B" .................................... 14

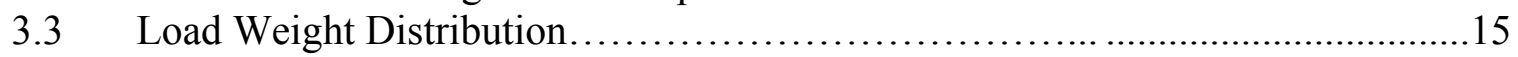

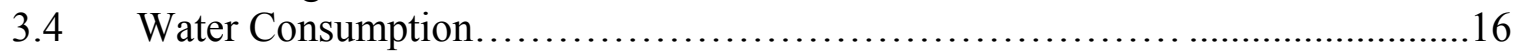

3.5 Washer Energy Consumption........................................... 18

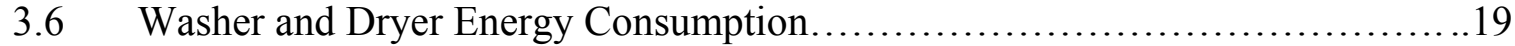

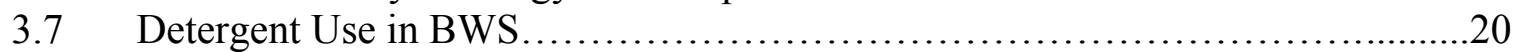

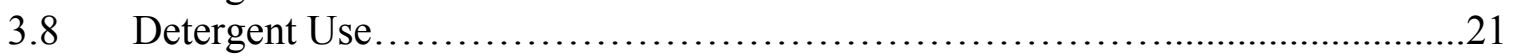

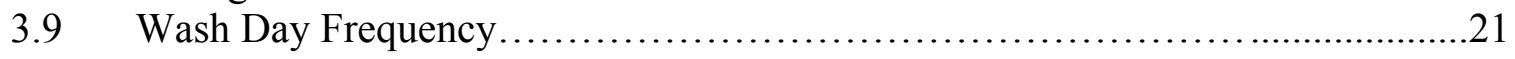

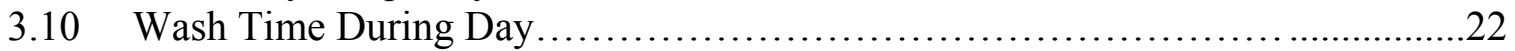

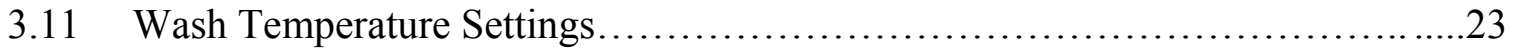

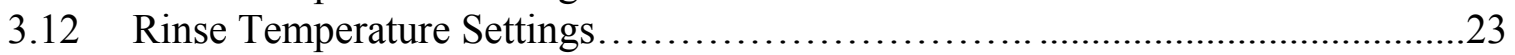

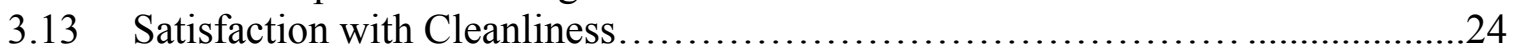

3.14 Dampness and Cleanliness Satisfaction Scores...............................25

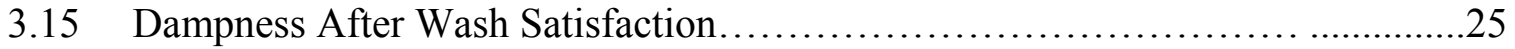

4.1 Dryer Energy Consumption by Load Weight Distribution......................28

4.2 Impact of Initial Load Moister on RMC Determinations...........................30

4.3 Remaining Moisture Content of Loads After Final Washer Spin by Load Weight Distribution..............................................................

4.4 Dryer Energy Consumption and Remaining Moisture Content........................31

4.5 Load Weight vs Dryer Energy Consumption........................................32

$5.1 \quad$ Overall Boston Washer Study Results......................................... 



\section{LIST OF TABLES}

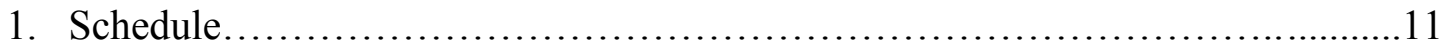

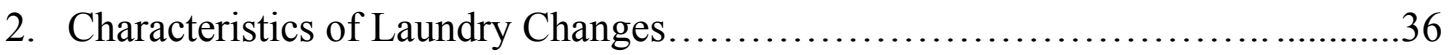

3. Completeness of Phase I and II Data Records.............................. 7

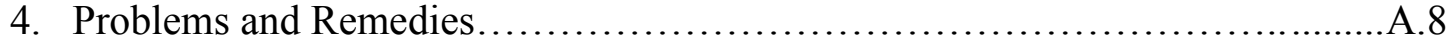

5. Measured Hot and Cold Water Temperatures ................................. 



\section{EXECUTIVE SUMMARY}

Surprising to many, conventional domestic clothes washers use about 40 gallons of water, water weighing more than 300 pounds, to wash a load of clothes which typically may weigh only six pounds. This fact combined with the knowledge that U.S. homes wash on average one load of laundry each day, makes clothes washers one of the highest end-uses of water in today's homes. About 35 billion loads of laundry are washed annually in the U.S. and this consumes $2.6 \%$ of the total residential energy use ${ }^{1}$. A relatively small amount of energy is used by the clothes washer itself to operate the motor and controls. A much larger component is the energy needed to heat the water used by the washer and the energy needed to dry clothes once they have been washed. Consequently, washers that have low water requirements and have effective spin cycles to remove moisture from the clothing thereby reducing the energy needed by the dryer, tend to be efficient, and, as long as the laundry throughput is not compromised, they save water and energy.

The majority of clothes washers produced for the U.S. consumer are vertical axis (v-axis) washers with a central agitator. While there are variations, most v-axis washers suspend the clothes in a tub of water for washing and rinsing. Horizontal-axis (h-axis) washers tumble the wash load repeatedly through a small pool of water at the bottom of the tub to produce the needed agitation. This tends to reduce the need for both hot and cold water. Today's market for high-efficiency washers is relatively small, but is growing with increased awareness of energy and water savings benefits. Market growth is also enhanced as federal standards for maximum energy consumption requirements have been tightened. Estimates have shown that a large quantity of energy and water could be saved through the replacement of conventional v-axis washers with high-efficiency designs. The objectives of this project were:

-To evaluate the energy and water savings of high-efficiency, h-axis washers and dryers in an urban community, which has been converted to the new design, -To demonstrate the findings, and

-To make the findings available to the public

Boston was selected as the location for this project. During phase I of the study, 50 clothes washers and 50 dryers in a condominium complex were instrumented so that data could be collected on laundry habits, laundry throughput, and energy and water consumption for each load of laundry. After $2 \frac{1}{2}$ months of data gathering, existing washers and dryers were replaced by new, horizontal-axis clothes washers and matching dryers, and the experiment continued for an additional $2 \frac{1}{2}$ months. Detailed data were collected and analyzed on more than 2,900 loads with nearly 15,000 pounds of laundry and 100,000 gallons of water used by the participants over a wide range of real-world conditions.

Overall, it was found that the changeover to the h-axis washer reduced the average water consumption by $41 \%$. The washer energy consumption including washer energy and hot water energy fell by $50 \%$ due to the hot water savings as well as more efficient motor and controls. The dryer energy savings for the study was $22 \%$, which was mainly attributed 
to the high speed spin cycle of the h-axis washer reducing the remaining moisture content of the clothing after wash. The participants also realized a 19\% savings in detergent amount from phase I to phase II of the project.

The data and subsequent analyses showed that across all loads, temperature settings, use of detergent and other additives, participants found the cleaning performance of the $h$ axis technology to be generally superior to the phase I v-axis washers, irrespective of their ages. Participants seemed to adapt easily to the h-axis design with many of their laundry habits remaining unchanged from phase I to phase II. 


\begin{abstract}
To help understand the relative performance gains of conventional and high-efficiency washers and to increase awareness of energy/water savings, the U.S. Department of Energy under its Emerging Technologies Program and in cooperation with Maytag Appliances conducted a field-evaluation of horizontal axis washers in a Boston, Massachusetts condo complex. Baseline washer and dryer performance and customer habits were established using 50 participants and their existing, instrumented washers and dryers for a $2 \frac{1}{2}$-month period. After the baseline was established, the machines were replaced with high efficiency tumble action washers and moisture sensing dryers, and tested for the next $2 \frac{1}{2}$ months. By information gathered, energy and water savings delivered by the h-axis washers as well as impacts on participants' washing habits and perceptions of cleaning performance were determined. Overall, participants saved $41 \%$ of the water and $50 \%$ of the energy that they would have used without a changeover to the new h-axis washer. The changeover also produced significant dryer energy savings due primarily to the high-speed final spin of the new washer.

The Boston Washer Study report details the experiment including instrumentation, data collection and analysis procedures and discusses the impacts on energy, water and detergent consumption as well as customer satisfaction with the technology.
\end{abstract}





\section{GLOSSARY}

\begin{tabular}{|c|c|}
\hline Btu & British thermal unit or 1054 joules of energy \\
\hline BWS & Boston Washer Study \\
\hline Cold & Cold water use of washer \\
\hline DOE & U.S. Department of Energy \\
\hline EF & $\begin{array}{l}\text { Energy Factor, the quotient of the volume of the tub in a washer } \\
\text { and the energy consumption of the washer (ft3/kWh/cycle) } \\
\text { according to DOE Test Procedure as detailed in } 10 \text { CFR Part } 430 \text {, } \\
\text { Subpart B, Appendix J. }\end{array}$ \\
\hline Field & $\begin{array}{l}\text { Field data or data collected in a "real world" setting such as a } \\
\text { person's home rather that in a tightly-controlled laboratory setting }\end{array}$ \\
\hline Gallons/load & Gallons of water used by the washer per load \\
\hline gpm & $\begin{array}{l}\text { Gallons per minute refers to the rate of water use (gallons) over a } \\
\text { minute time period }\end{array}$ \\
\hline h-axis & $\begin{array}{l}\text { Horizontal-axis washer design in which the axis of rotation of the } \\
\text { washer drum is parallel to the floor on which the washer sits }\end{array}$ \\
\hline Hot & Hot water use of washer \\
\hline kWh & Kilowatt-hour of energy equivalent to $3413 \mathrm{Btu}$ \\
\hline Lb or Ibs & $\begin{array}{l}\text { A pound which is a measurement of weight equal to } 2.2046 \\
\text { kilograms }\end{array}$ \\
\hline Load or cycle & $\begin{array}{l}\text { A complete wash/rinse/spin cycle of a washer or a complete } \\
\text { cleaning of dirty clothes }\end{array}$ \\
\hline MEF & $\begin{array}{l}\text { Modified Energy Factor, the quotient of the volume of the tub in } \\
\text { the washer and the total clothes washer and dryer energy } \\
\text { consumption as determined through laboratory test procedure. }\end{array}$ \\
\hline ORNL & $\begin{array}{l}\text { Oak Ridge National Laboratory, Oak Ridge, Tennessee, managed } \\
\text { for the U.S. Department of Energy by UT-Battelle }\end{array}$ \\
\hline Phase I & $\begin{array}{l}\text { First } 2 \frac{1}{2} \text { months of the Boston Washer Study using conventional } \\
\text { v-axis washing machines }\end{array}$ \\
\hline Phase II & $\begin{array}{l}\text { Last } 2 \frac{1}{2} \text { months of the Boston Washer Study using h-axis } \\
\text { washers }\end{array}$ \\
\hline RMC & $\begin{array}{l}\text { Remaining Moisture Content, the ratio of the weight of water left } \\
\text { in the clothes after washing and the dry weight of the clothes }\end{array}$ \\
\hline Total Water & Hot plus cold water use of washer combined \\
\hline v-axis & $\begin{array}{l}\text { Vertical Axis (conventional washer design) in which the axis of } \\
\text { rotation of the washer agitator is perpendicular to the floor }\end{array}$ \\
\hline
\end{tabular}





\section{OVERVIEW AND OBJECTIVE OF THE FIELD STUDY}

Appliance manufacturers are producing high-efficiency residential clothes washers for the U.S. market, based on horizontal and vertical axis technologies. Horizontal axis machines are designed to tumble the clothing through a small bath of water, rather than being immersed in a tub of water, as is typically done by most washers. Lab data and previous field experiments have shown that these machines save around $55 \%$ to $60 \%$ of the energy needed and $40 \%$ of the water needed for a conventional, vertical axis washer ${ }^{2}$. It had also been suggested that dryer energy can be saved through the faster spin cycle of the h-axis washer. The high-speed spin should leave less moisture in the clothing thereby reducing the dryer time and dryer energy consumption. Although savings produced by high-efficiency washers have been measured in the laboratory and through limited field experiments, field measurement of the effects of lower moisture on dryer energy consumption has not been done. This study provides that information.

Prior field studies of h-axis washers have taken place in single-family homes where there were usually children and working parents. In these prior studies, all of the washers and dryers were of the side-by-side type, and load numbers and types of clothes were representative of what would be expected in a residential or rural setting. Of particular applicability to the urban market are washers with stackable dryers, and manufacturers are beginning to feature the h-axis technology in a stackable version. One example is Maytag's new Neptune washer with stackable dryer. This washer features a higher spin speed than the original Neptune (1000 rpm vs. $800 \mathrm{rpm}$ ), an internal heater to better control wash and rinse temperatures, new tumble and spin patterns aimed at improved cleaning, and other features (e.g. touch-screen controls) that do not materially affect the washer's efficiency. The effect of these improvements on washer performance and the effect of the higher spin speed in improving the dryers' efficiency had not been determined at the outset of this project. This study, therefore, was undertaken with these objectives: (1) performance evaluation of a stackable h-axis washer and dryer, (2) measured effect of reduced moisture content from a higher spin speed on dryer energy consumption, and (3) determination of the energy and water savings that might be experienced by a condominium, apartment or other urban resident from a changeover to the high-efficiency washer.

The Boston Washer Study (BWS) - To evaluate the real-world performance of haxis washers, their impact on dryer energy consumption, and to help bring about increased awareness of the benefits of this technology, Reading, Massachusetts, a Boston suburb, was chosen as a test bed for evaluating the performance and acceptability of haxis washers in an urban environment. The 5-month BWS consisted of (A) gathering water and energy consumption data on the existing washing machines to establish a baseline against which the water and energy use pattern of high-efficiency washers and dryers can be measured, (B) switching out these washers with high-efficiency models, and $(\mathrm{C})$ determining the savings in water, energy consumption for the washer and dryer, and changes in laundry habits and other impacts experienced by the participants from a changeover to the h-axis machines. 
The BWS was conducted by Oak Ridge National Laboratory and Maytag Appliances with additional participation by Boston Gas and Northeast Energy Efficiency

Partnerships Inc. Distribution of project results to the public is an important objective of the study. 


\section{INITIATING THE PROJECT}

\subsection{SITE SELECTION CRITERIA}

A similar experiment was conducted a few years ago in a farming community in Kansas. Participant work habits, occupations and family size affect laundry patterns (e.g. load size, frequency, type of clothing), and it was expected that there would be some differences in the results of the prior studies and a study to be conducted in an urban setting. Specific considerations in the selection of a site for the study were the following:

- Urban Setting. An urban setting (apartment complex) would be a major departure from the single family homes in the farming community previously examined. A metropolitan environment would produce different laundry habits due to occupation variation. The site would need to be a centrally located area, preferably one building, to allow ease of monitoring and project awareness by residents. Resources limited the experiment to experimental analysis of less than 75 resident participants, and this meant that an apartment or condominium complex of 100 units or less would be desirable, assuming that a lesser number of people would actually participate.

- Presence of high water and energy costs. A community that had high water and energy costs would be more aware of savings particularly if evident on utility bills. Furthermore, the higher savings would help to improve the economics and market for high-efficiency washers.

- Fast growing area. Locations with a fast growing economy and population place growing demands on the existing utilities infrastructure. Information from the study would be useful to help stem growth in water and energy consumption as well as wastewater production would extend the life of the existing community's utility resources.

- Participants' willingness and enthusiasm. The resources allocated to this project were not sufficient to allow an automatic data acquisition system to be installed in each residents dwelling. Therefore, we designed the study so that the data to be gathered from this experiment would be taken by participants reading instruments, and recording the information in a data logbook. The people selected would need to write down data from the instruments and their perceptions of each load, accurately and consistently throughout the 5-month experiment. In order for the field study to be successful, a location with willing and interested people would need to be selected.

\subsection{BOSTON LOCATION SELECTED FOR FIELD TEST}

With the assistance of the Northeast Energy Efficiency Alliance and other contacts, a search was made of apartment buildings or high-rise condominiums that would meet the selection criteria. The process involved a review of selected buildings to examine ones that had distributed laundry appliances, met the size criteria, were fully occupied with long term residents, and possessed electric rather than gas dryers. The Summit Terrace 


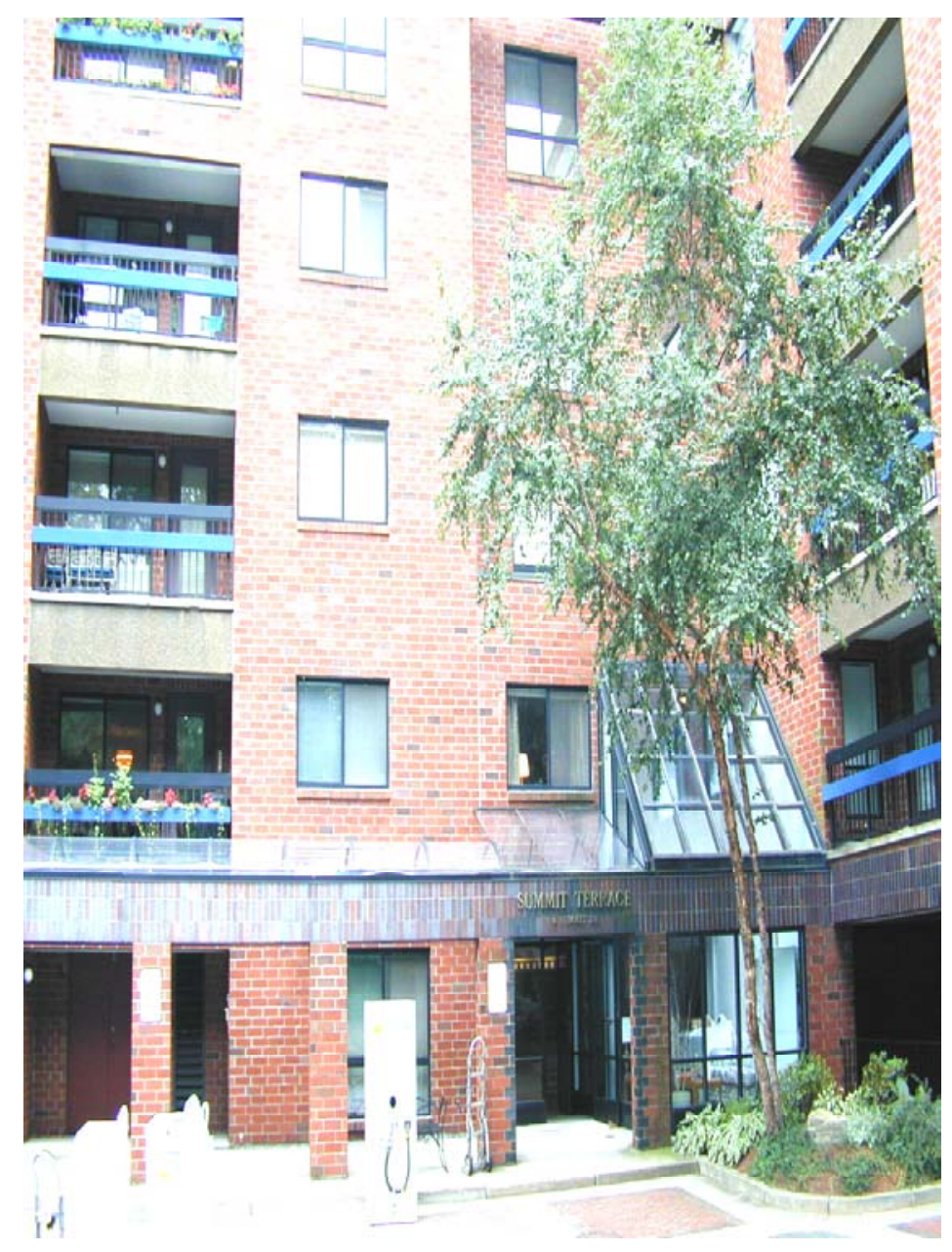

Figure 2.1 Summit Terrace Condominium Complex condominiums in Reading, Massachusetts - a community on the I-95 beltway around Boston fully met the requirements of the project. The condo (shown in Figure 2.1) consists of six floors and 67 condo units. Space heating is provided by a natural gas boiler and hydronic distribution systems. Each unit is assessed a monthly utility fee for heating depending on the unit's size. Each unit is separately metered for electricity.

\subsection{BOSTON, MASSACHUSETTS}

Neighboring Boston is a large metropolitan area with a unique historical background and a booming economy. With the surge in the number of businesses locating themselves in the city, comes an expected growth in the number of residents the city must service. As growth continues, Boston's infrastructure must expand at a comparable rate, unless moderated through conservation and efficiency improvements.

Reading's water/wastewater rates are almost four times the national average at $\$ 12.00$ per 1000 gallons of water ${ }^{3}$. The electricity rates are between $\$ 0.09-\$ 0.13$ per $\mathrm{kWh}$, again higher than the national average of 8.17 cents per $\mathrm{kWh}^{4 \& 5}$. Because of these high costs and population growth, savings in water, energy, and wastewater are important to the public for it reduces utility costs, and to the utilities who are stretched to meet a growing demand for resources. 


\subsection{PARTICIPANT SELECTION}

Project information along with a survey form and invitation to join the project were mailed to each of the 67 homeowners in the condo complex. The residents were informed of the project's goals and that to participate, they would be required to help. The homeowners (Figure 2.2) were told that as participants, they would need to record information about each load of laundry for the entire experimental duration of 5 months. The first $2 \frac{1}{2}$ months would involve data collection on their existing machines after

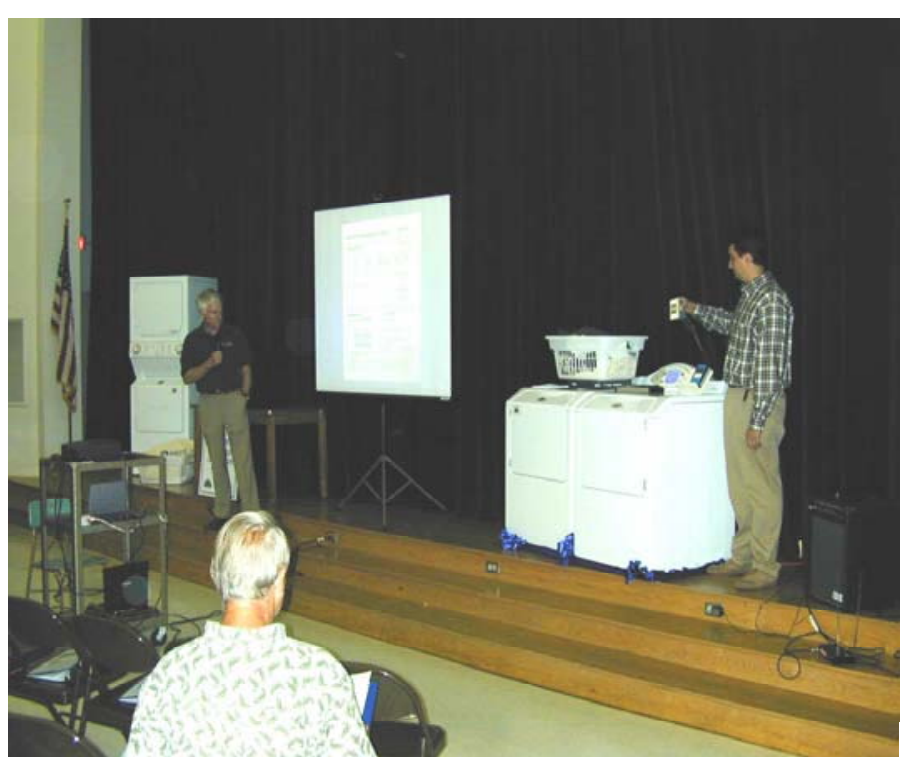

Figure 2.3 Introductory Meeting with Participants

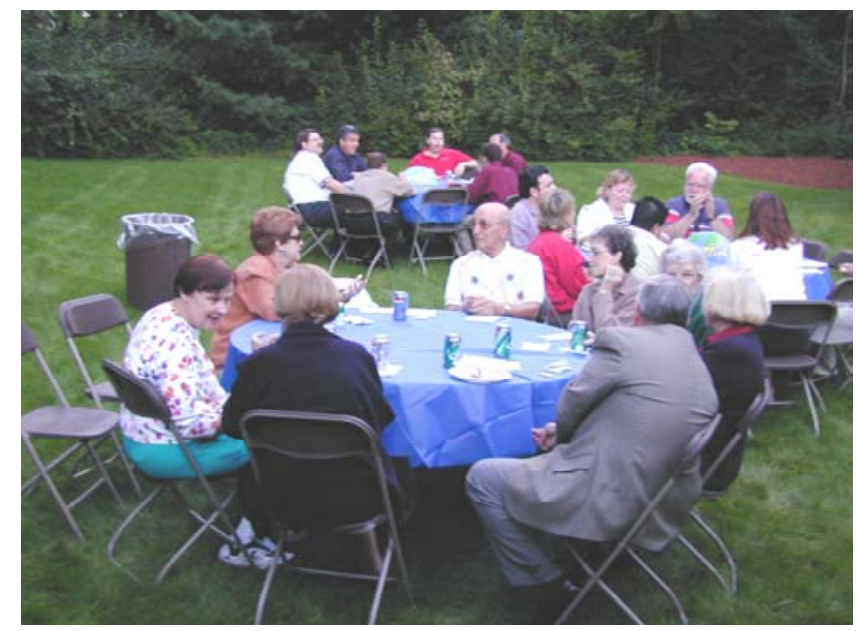

Figure 2.2 Participants in Study

which their machines would be replaced with Maytag Neptune washers and dryers for the remaining $2 \frac{1}{2}$ months. In return for their cooperation and assistance, the participants could elect to keep the new washer if they so desired.

Responses from the 67 residences indicated that 50 would be able to participate. The remaining 17 units were not able to participate for a number of reasons such as: extended vacation, too busy, out of town, among others. The 50 participants then filled out a questionnaire asking about their laundry habits and machines

characteristics they currently own. A meeting about the project (Figure 2.3) was held on May 9, 2000 in Boston to inform the residents of their responsibilities, give an overview of the experiment, and answer questions. 
Information gathered from the residents through the survey revealed the following:

General Information

- $\quad 28 \%$ of units had 2 residents;

- $\quad 2 \%$ of units had 3 residents;

- $\quad 70 \%$ of units had 1 resident;

- $\quad$ The average age of the residents was above 50 .

Laundry behavior and equipment:

- $\quad 76 \%$ of the residents had stacked washer and dryer units ( $24 \%$ had sideby-side);

- $\quad$ The washers and dryers were all electric;

- $\quad$ Residents estimated that the average number of loads washed per week was 4;

- $\quad$ The ages of the washers and dryers: $32 \%$ less than 5 years old, $18 \%$ were 6-10 years old, and $50 \%$ were $11-15$ years old;

- $\quad$ Residents were evenly split between those who washed in hot and those who washed in cold water;

- $\quad$ Sizes of the loads were: $4 \%$ small, $46 \%$ medium, and $50 \%$ large;

- $\quad 78 \%$ of the machines were Maytag, $10 \%$ Kenmore, and $12 \%$ Others.

The ages of the washers are important because it helps determine the benefit of changing to new high efficiency machines. The older the machine, the greater the opportunity for energy and water conservation. Because $50 \%$ of the machines were older than 10 years, this means that the average household's appliances can and do last longer than estimated lifespan for these products. It is unique that $78 \%$ of the residents owned Maytag machines; this is well above the national average for Maytag washers and dryers.

\subsection{EXPERIMENT}

\section{DESIGN}

A central objective of the field study was to determine the impacts of replacing existing, conventional washers and dryers with high-efficiency, horizontal axis washers and dryers. The potential impacts include the following:

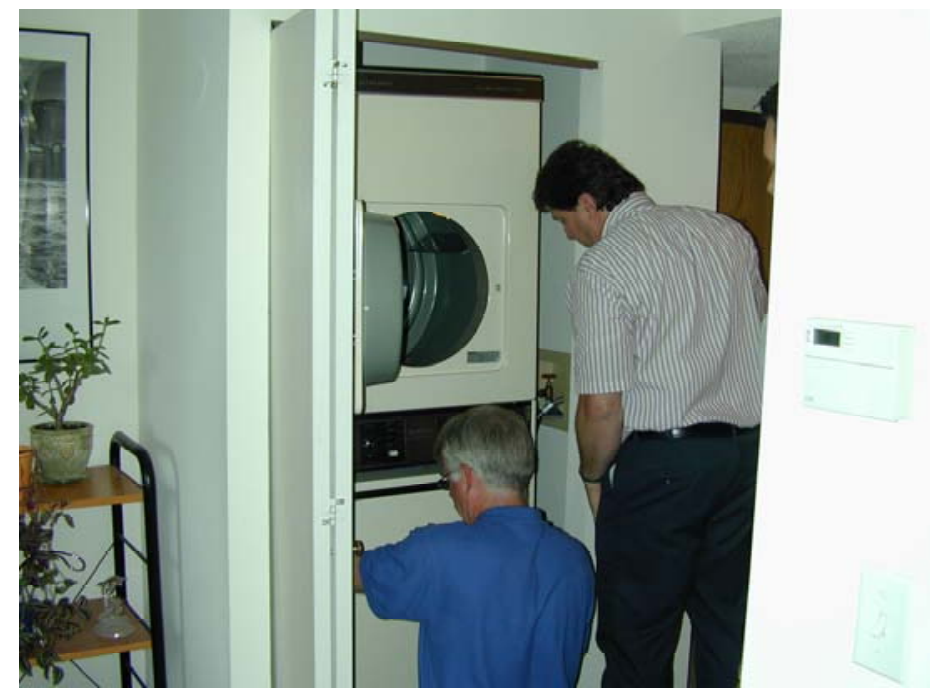

Figure 2.4 Phase I Instrumentation Installation 
- $\quad$ Changes in water consumption;

- $\quad$ Changes in electrical energy consumption of the washer as well as energy changes from reductions in the amount of hot water used;

- $\quad$ Changes in dryer energy consumption;

- $\quad$ Changes in load weights. Differences in capacities and how participants load machines will affect load weights;

- $\quad$ Changes in detergent use;

- $\quad$ Changes in the "dryness" of loads removed from the washer. The ability of the washer to extract water in the final spin affects the energy needed by the dryer;

- $\quad$ Changes in the time needed for the washing and drying cycles;

- $\quad$ Changes in customer satisfaction as related to cleaning/drying performance;

- $\quad$ Changes in existing laundry habits.

The (phase I) experimental design included individually metering each participant's conventional washer and dryer, and having the participants record data from their instrumentation for each load for $2 \frac{1}{2}$ months (Figure 2.4). Following phase I, each participant's washer and dryer were replaced by high-efficiency, horizontal axis washers and dryers (Figure 2.5), the instrumentation reinstalled (Figure 2.6), and the experiment continued for an additional $2 \frac{1}{2}$ months (phase II of the project). The changes in performance, energy and water consumption, laundry patterns, participant satisfaction, and other potential impacts listed above were determined by comparing phase I and phase II data.

\subsubsection{Instrumentation}

Water Meters - Two water meters (Figure 2.7) were installed on each washer in the project - one to measure the hot water consumption and the other for the cold. These meters (Badger Model 50) had been modified and adapted to work with a remote digital readout. The meter modification detailed in Appendix A, provided the readout with a least count of almost $1 / 200$ of a gallon.

Participants simply recorded the readings from the hot and cold readouts after each load of laundry was completed, and the conversion of these

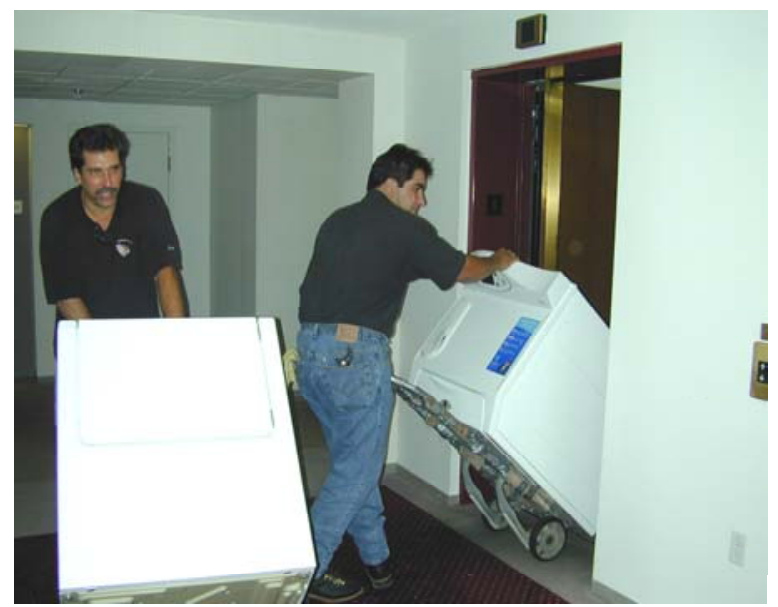

Figure 2.5 Phase II Installation readings into gallons of water was done by ORNL during the data analysis portion of the project. 
Laundry Basket - Each participant was given a standard laundry basket to use for weighing the loads. This simplified determination of load weights across the participants.

Weighing Scale - Each participant was given a digital scale (Figure 2.7) for weighing wash loads to a precision of 0.01 of a pound. The participants weighed each load using the standard basket after the wash was completed and again after the load was dried. All recorded weights included the weight of the clothes and the laundry basket. As part of the analysis, load weights were determined by subtracting the weight of the basket from recorded weights.

Measuring Cup - Each participant was given a standard detergent cup to measure detergent use for each load. As before, participants recorded detergent use on individual load data sheets.

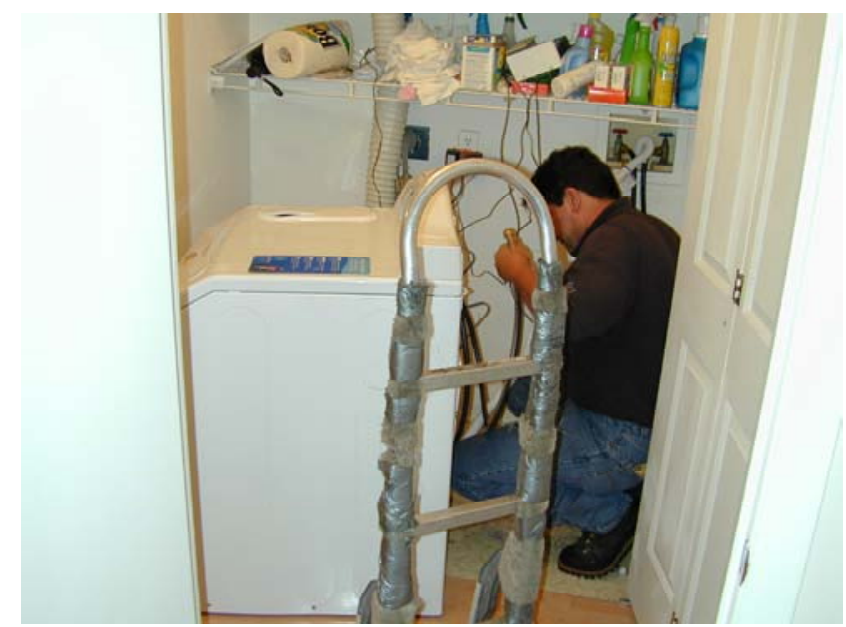

Figure 2.6 Phase II Instrumentation Installation

Temperature Measurements - As the water meters were installed on each machine during

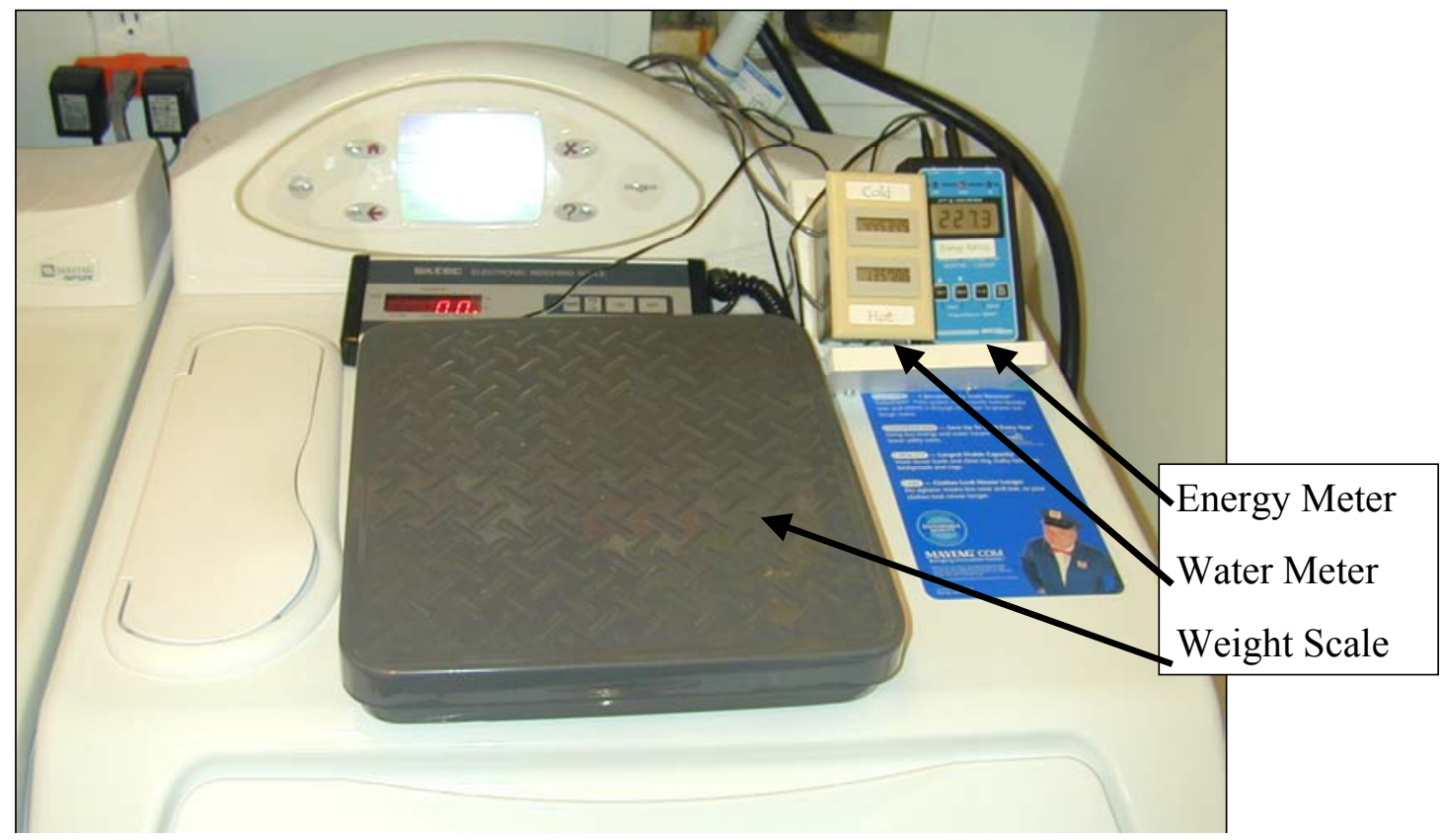

Figure 2.7 Instrumentation

the first week of the study, hot and cold water temperatures were carefully measured by the installation team and used in the analysis. These temperatures were measured once again during the changeover to the new machines. 
Dryer Energy Meter - An energy meter (Figure 2.8) was installed to measure the energy consumed by the dryer. Specially designed adapters were built specifically for this project to measure the total power to the dryer. The participants read the energy meter and recorded the energy consumption after each load was dried. In most instances, participants' machines were stack units that had a single plug to power both the washer and dryer. In these cases, careful attention was taken during the analysis phase to determine the washer versus dryer energy consumption, through subtracting the average washer electrical energy consumption from the total recorded on the meter.

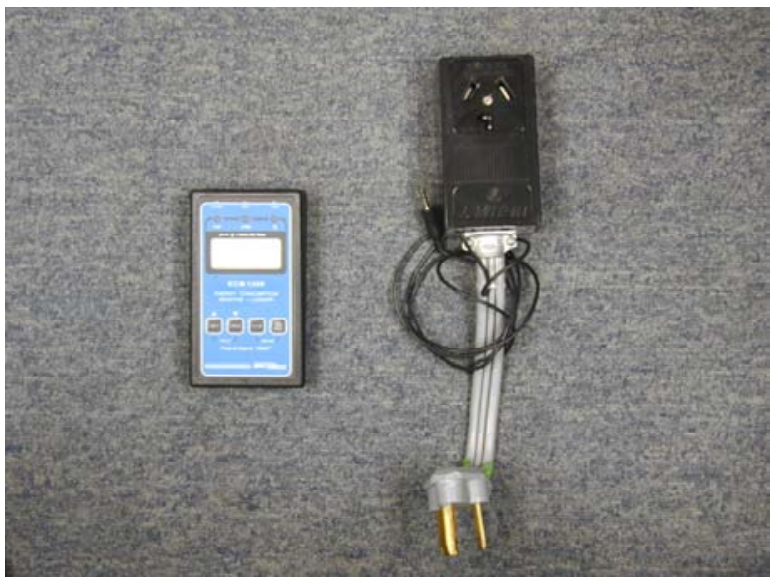

Figure 2.8 Dryer Energy Meter

Machine Energy Consumption - The electrical energy consumption (kWh required to operate the washer's motor and controls for a cycle) of most of the original Phase I washers in the study was determined from available data based on brand and model number. In those cases where a machine was too old and energy consumption information was unknown, machine energy consumption was taken to be the average of the machine energy consumption of the remaining phase I machines. This provided a conservative (lower energy use) estimate for the older machines. To determine the electrical energy consumption for the phase II washers, we selected a few participants, and used an energy meter to determine washer energy consumption on different settings. An average for all the tested loads was calculated and used as the washer electrical energy consumption for all the loads during phase II of the project.

Data Sheets/Notebook - Finally, each participant in the project was given a notebook containing data sheets (Figure 2.9) to be filled out - one for each load of laundry, and a set of instructions for data entry and managing the notebook. The sheets were divided into three sections: Before Wash, After Wash, and After Dry. The information for each of these sections was filled out by the participants and included the following:

Before Wash: Date, Time, Detergent Amount, Detergent Type, and Machine Settings (Load Size, Wash Temperature, and Rinse Temperature);

- $\quad$ After Wash: Load Weight, Cold Water Reading, Hot Water Reading, and Satisfaction with the Dampness of the Load After Dry: Load Weight, Energy Reading, and Satisfaction of Cleanliness of Load. 


\section{BEFORE WASH}

\begin{tabular}{|c|c|c|c|}
\hline \multirow{2}{*}{$\begin{array}{ll}\text { 1. } & \text { Month } \\
\text { Number }\end{array}$} & \multirow{2}{*}{ (Fill in day of month) } & \multicolumn{2}{|c|}{ Time } \\
\hline & & & \\
\hline & $\begin{array}{l}\text { (Fill in day of month) } \\
\text { (Calendar at left) }\end{array}$ & $\mathbf{A M}$ & PM \\
\hline
\end{tabular}

2. Detergent Amount (cups)

\begin{tabular}{|llll|}
\hline $1 / 4$ & $1 / 2$ & $3 / 4$ & 1 \\
$1 \frac{1}{4}$ & $1 \frac{1}{2}$ & $13 / 4$ & 2 \\
\hline
\end{tabular}

\section{Detergent Type}

Tide HE

Other
3. Machine Settings

\section{Load Size}

\begin{tabular}{|ll|}
\hline Mini & Large \\
Small & X-Large \\
Medium & \\
\hline
\end{tabular}

\section{Wash Temperature}

Hot

Warm

Cold

Rinse Temperature

Warm

Cold

\section{ATHER WASH}

4. Load Weight lbs

5. Cold Water Reading

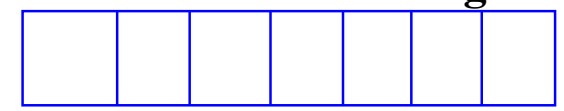

Hot Water Reading

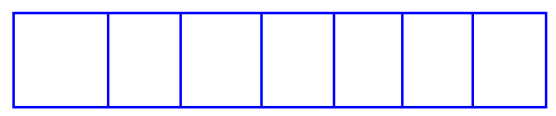

6. Satisfaction with dampness of load after wash cycle:

Completely Satisfied

Very Satisfied

Somewhat Satisfied
Not Very Satisfied

Not at all Satisfied

\section{AFTER DRY}

7. Load Weight

lbs

8. Energy Reading kWh

9. Satisfaction with Cleanliness of Load:
Completely Satisfied

Very Satisfied

Somewhat Satisfied
Not Very Satisfied

Not at all Satisfied
Mail completed forms on the $15^{\text {th }}$ and $30^{\text {th }}$ of each month to David Durfee in the self-addressed, no 


\subsubsection{Schedule}

The schedule for the study is given in Table 1, below:

Table 1 Schedule

\begin{tabular}{|l|l|}
\hline Date & Project Activity \\
\hline February, 2000 & Request for homeowner participation - letter \\
\hline May 9, 2000 & $\begin{array}{l}\text { Project overview to participants - Joshua Eaton School } \\
\text { cafeteria in Reading, Massachusetts }\end{array}$ \\
\hline May 23-25, 2000 & $\begin{array}{l}\text { Installation of metering equipment on current washers } \\
\text { and dryers; distribution of notebooks }\end{array}$ \\
\hline June 1,2000 & Phase I data collection begins \\
\hline Aug 21-24, 2000 & $\begin{array}{l}\text { Removal of current washer and dryer; Neptune washer } \\
\text { and dryer installation; re-installation of instrumentation; } \\
\text { initiation of phase II data collection; discussion with } \\
\text { each participant about his or her specific laundry data } \\
\text { already collected and analyzed }\end{array}$ \\
\hline October 21, 2000 & Phase II data collection ends \\
\hline October 28, 2000 & $\begin{array}{l}\text { Announcement of preliminary findings at Boston } \\
\text { Symphony Hall by DOE and Maytag }\end{array}$ \\
\hline $\begin{array}{l}\text { October 30 - November 1, } \\
\text { 2000 }\end{array}$ & Removal of Instrumentation \\
\hline $\begin{array}{l}\text { November 2 - January 15, } \\
\text { 2001 }\end{array}$ & Data Analysis \\
\hline May 15, 2001 & Individual reports to participants \\
\hline September, 2001 & Final project report completed \\
\hline
\end{tabular}

Recognizing the importance of the participants to continue taking data as an essential

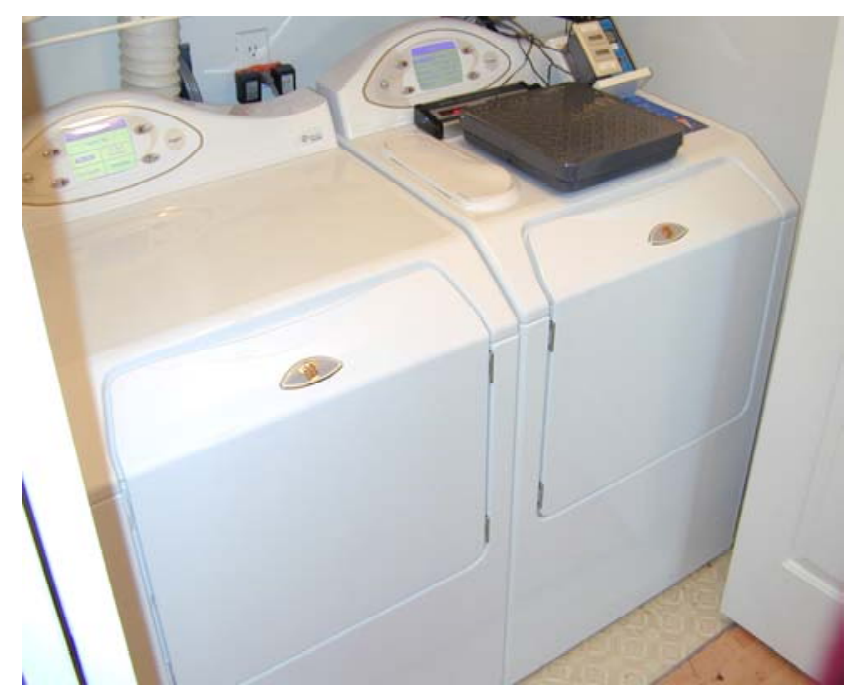

Figure 2.10 Phase II Machines with Instrumentation element to the project's success, an aggressive schedule was set to ensure that data were collected and analyzed efficiently. During the entire experiment, we remained in close contact with each participant (through emails, phone calls, and site visits) to check procedures being used and to support their continued interest in the project. During the phase II installation of the participants' new washers and dryers, researchers from ORNL discussed with each person findings from individual results and how they compared to study averages. 


\subsection{DATA COLLECTION AND ANALYSIS PROCEDURE}

The overall approach to the data being gathered was to have the ability for each participant's data to be viewed separately as well as collectively. We used routines in Microsoft Excel 2000 to accomplish this task. The following analysis sequence was used: participants recorded data for each load, data was mailed to ORNL on the $15^{\text {th }}$ and $30^{\text {th }}$ of each month for analysis, the data was entered into Excel, results were calculated, and charts created for display of the results.

Each person's data was entered into a separate worksheet of a single file. There were 50 worksheets, one for each participant, and one summary worksheet where all the data was tied together. Each participant's worksheet contained calculated results and charts for that individual. This allowed researchers at ORNL to determine and resolve data collection problems quickly. Individual worksheets allowed a tremendous amount of flexibility which would not have been easily accomplished with all the data going into one database or worksheet. Individual worksheets allowed ORNL to correct data due to: incorrect recordings, load weight errors, energy meter resetting, missing data, water meter malfunctions, as well as other potential problems.

The integrity and quality of the data collected from the Boston participants during both phases of the study is discussed in Appendix C.

After each participant's worksheet calculations were made, summary calculations for each individual were analyzed for errors and data quality checking. Following these summary calculations, individual summary statistics were compared to overall statistics from the study.

Based on this process, data from around 3000 loads of laundry were taken and analyzed to address the objectives of the study. The results are reported in the next section. 


\section{OVERALL FINDINGS AND IMPACTS}

Compared to conventional machines, high efficiency washers are designed to reduce significantly the amount of water that they consume. The reduction in water consumption is accompanied by savings in energy that is used to provide hot water. The energy that is saved directly by high efficiency washers depends on the fraction of total water consumption that is hot. Moreover, the high final spin speed of the h-axis washer allows more water to be extracted from each load prior to placement in the dryer. This reduces the amount of moisture that must be eliminated by the dryer. Dryer times are reduced, and the dryer then uses less energy for each load. Although there have been several prior field evaluations of the performance of the h-axis washer as compared with existing washers including the 1997 study in Bern, Kansas ${ }^{2}$, none to our knowledge evaluated the washer's impact on dryer energy consumption. Knowledge of the amount of moisture in each load entering the dryer and the dryer energy consumption allowed the BWS to determine the impact of the high-efficiency washer on dryer energy consumption. Further, the BWS evaluated the h-axis technology using different laundry habits, clothing types and laundry throughput in an urban setting as compared to the rural setting in the prior study. In subsequent sections of this report, we evaluated the impact of the h-axis washer changeover on hot and cold water consumption, energy consumption of the washer and dryer, drying time, load size, detergent usage and participant satisfaction with respect to cleaning performance and water extraction by the washer.

\subsection{IMPACTS ON LOAD SIZE}

We assumed that over the duration of the BWS, the mix of clothing types washed in an average load of laundry would remain the same for an individual participant. For example, a participant would be as likely to make up loads of heavy items (e.g. sheets and towels) and light items (e.g. shirts and delicates) in the same way during Phase I as during Phase II. This means that the density (weight/volume) of an average load would remain unchanged over the course of the study. As a consequence, we were able to characterize load weight (a quantity that we could determine accurately) as the measure of load size.

The larger the size of each load, the fewer the number of loads that must be washed. This has the potential for saving water, energy, detergent and time. The Phase I washers had a load size selector that could be adjusted for larger or smaller loads by the participant. This setting determines the fill level of the water in the tub allowing the user to match the size of the load with the proper amount of water in the tub. If the load size setting is switched to the "large load" position to wash a small load, more wash and rinse water is used than is needed. When the setting is used as designed, less water is used.

In Phase I of the BWS, we found that some residents made use of the load size selector for most loads while others did not. Figure 3.1 shows the load size selector use pattern for one participant (Participant "A") in the study. The load weights were binned in 2pound intervals, and the scale on the horizontal axis represents the maximum load in each bin. With the selector switch on the "large" setting, this participant washed loads 


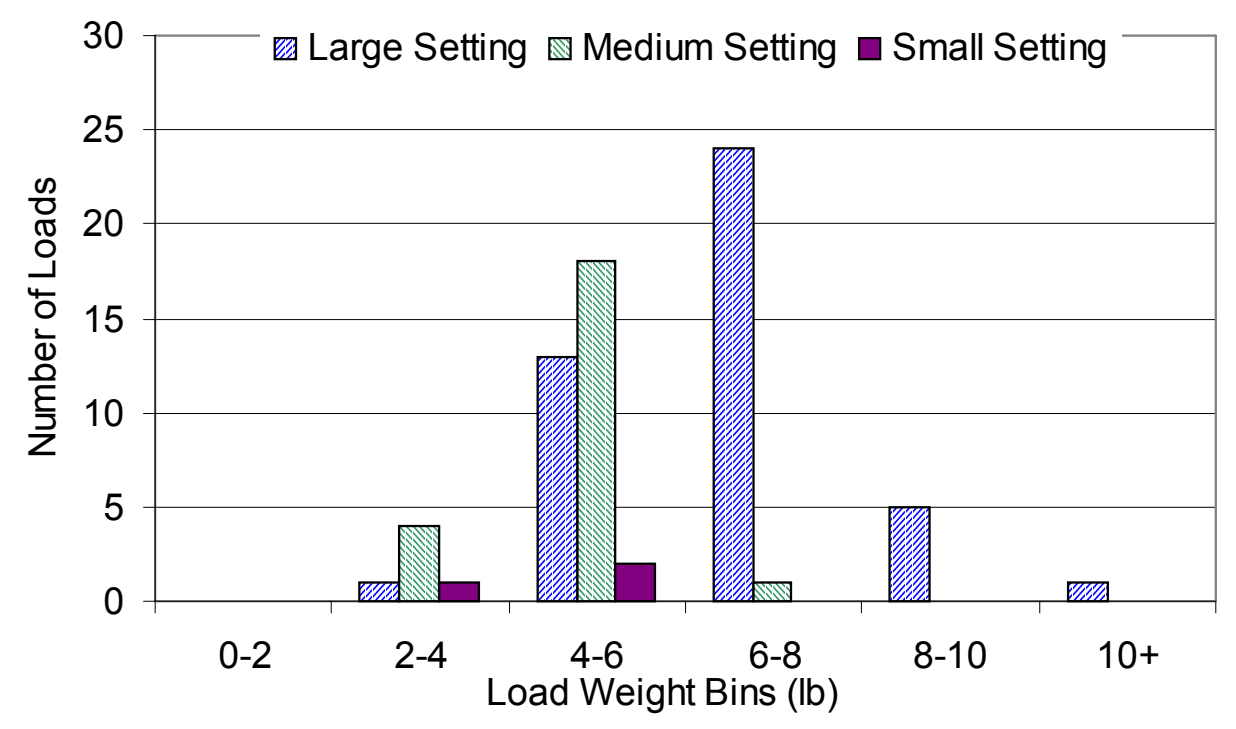

Figure 3.1 Phase ILoad Settings for Participant "A".

weighing from 2 pounds to more than 10 pounds. The most frequent load size was 6-8 pounds, with a few loads weighing much less and some loads that weighed 10 or more pounds. Under the "medium" setting, the most frequent load size was 4-6 pounds, and no loads heavier than 6 pounds were washed. Very few loads were washed using the "small" setting. More loads overall were washed using the large setting than for either of the other two settings, and interestingly, all three settings were used for loads in the 4-6pound bin. For the most part, participant " $A$ " appeared to apply the setting for most loads.

Figure 3.2 shows similar data for participant "B".

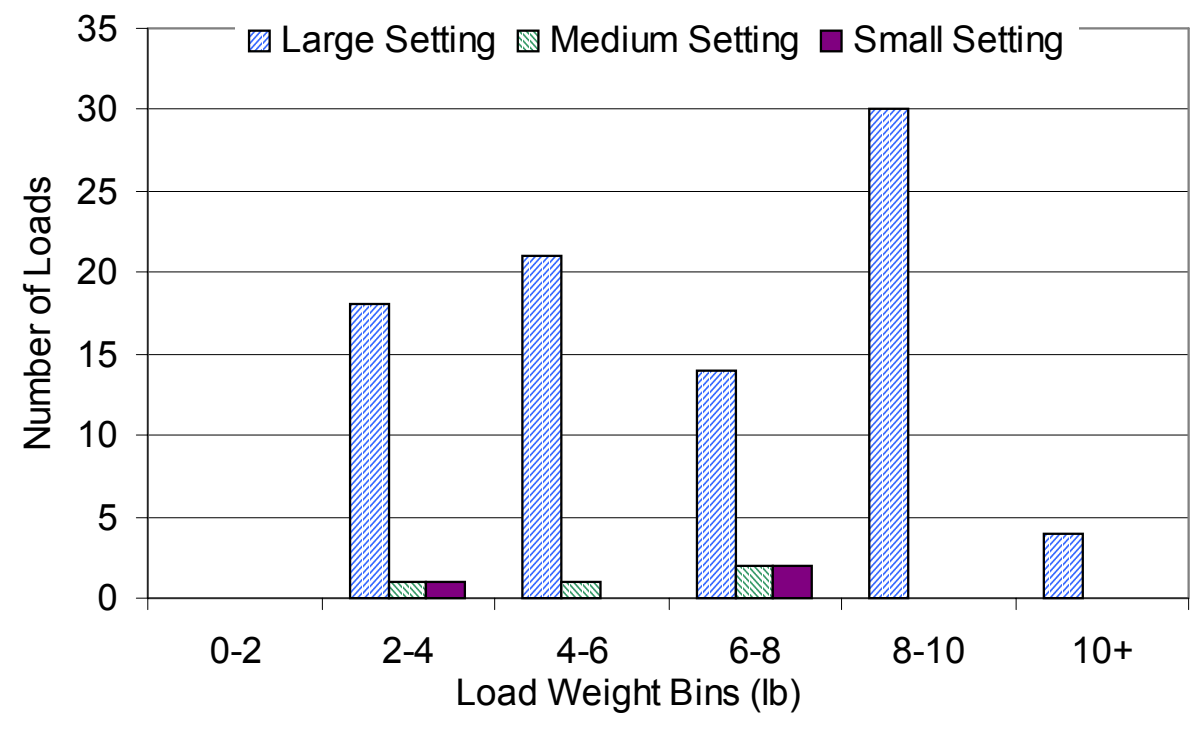

Figure 3.2 Phase ILoad Settings for Participant "B". 
It is apparent that this participant left the selector switch on the "large load" setting for most of the loads including very light ones. Although participant "B" most frequently washed loads weighing 8-10 pounds, there were a number of loads that weighed much less, and for these loads, a lower setting could have been used and would have produced savings in water and possibly energy as well. The habits of most of the other participants in the study fell in between those of participants " $A$ " and " $B$ ".

The design of the phase II, h-axis washer eliminated the need for the load size setting. The amount of water in the tub of the h-axis machine is determined and controlled automatically by a pressure sensor at the bottom of the tub. The sensor operates a fill solenoid valve to maintain the proper level of water in the machine for all wash and rinse cycles and for all types of loads. Since the water levels in the h-axis washers were controlled automatically, there are no corresponding data to what is shown in Figures 3.1 and 3.2 for phase II.

Participants measured and recorded load weights after washing and drying for each load washed during both phases of the Study. Incorrect weighings that failed to include the tare weight of the laundry basket were corrected in the analysis phase of the experiment by examining the reasonableness of the weight data before and after the dryer cycle. Figure 3.3 shows the distribution of load weights for both phases of the BWS and how this distribution changed between phases. The values shown are load weights after the

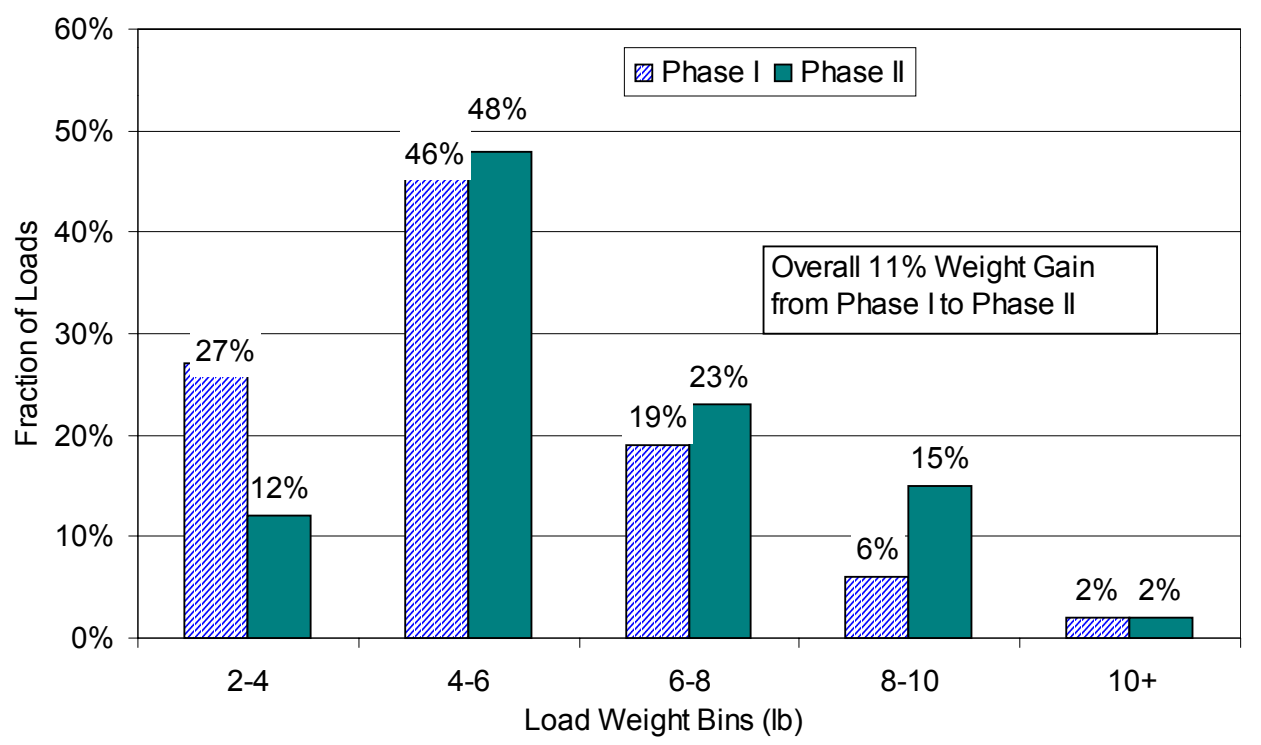

Figure 3.3 Load Weight Distribution for Phases I and II

drying cycle, and these would be a little less than the load weights into the washer. Across both phases of the Study, we found that most of the loads weighed from 4 to 6 pounds. Figure 3.3 also shows that the fraction of loads in the 2-4-pound group dropped, and the fraction of loads in the 8-10-pound group rose from phase I to phase II. This trend away from smaller load sizes suggests that the average load weight would increase after the washer changeover. Indeed, the average phase II load weight rose from 5.21 to 
5.77 pounds - an $11 \%$ increase. These weights are smaller than the average load weight determined through the field study conducted three years ago in Bern, Kansas. In that study, the average load weight was determined to be 6.98 pounds; however, the changeover to the h-axis washer produced only a $6 \%$ increase in average load weight. The results from the BWS are based on measurements from 1695 loads $(8,087$ pounds) of laundry in phase I and 1214 loads (6,565 pounds) of laundry done in phase II.

\subsection{WATER CONSUMPTION}

Water consumption for a clothes washer cycle depends on the cycle used and on the amount (weight) of the load. Small loads washed using a cycle with a single rinse would use much less water than larger loads and cycles with multiple rinses. We did not determine the cycle settings of the washers; however, we did measure the amount of both hot and cold water used with each load for both phases of the BWS. Figure 3.4 shows the cold, hot, and total water consumption per pound of laundry for each phase of the project.

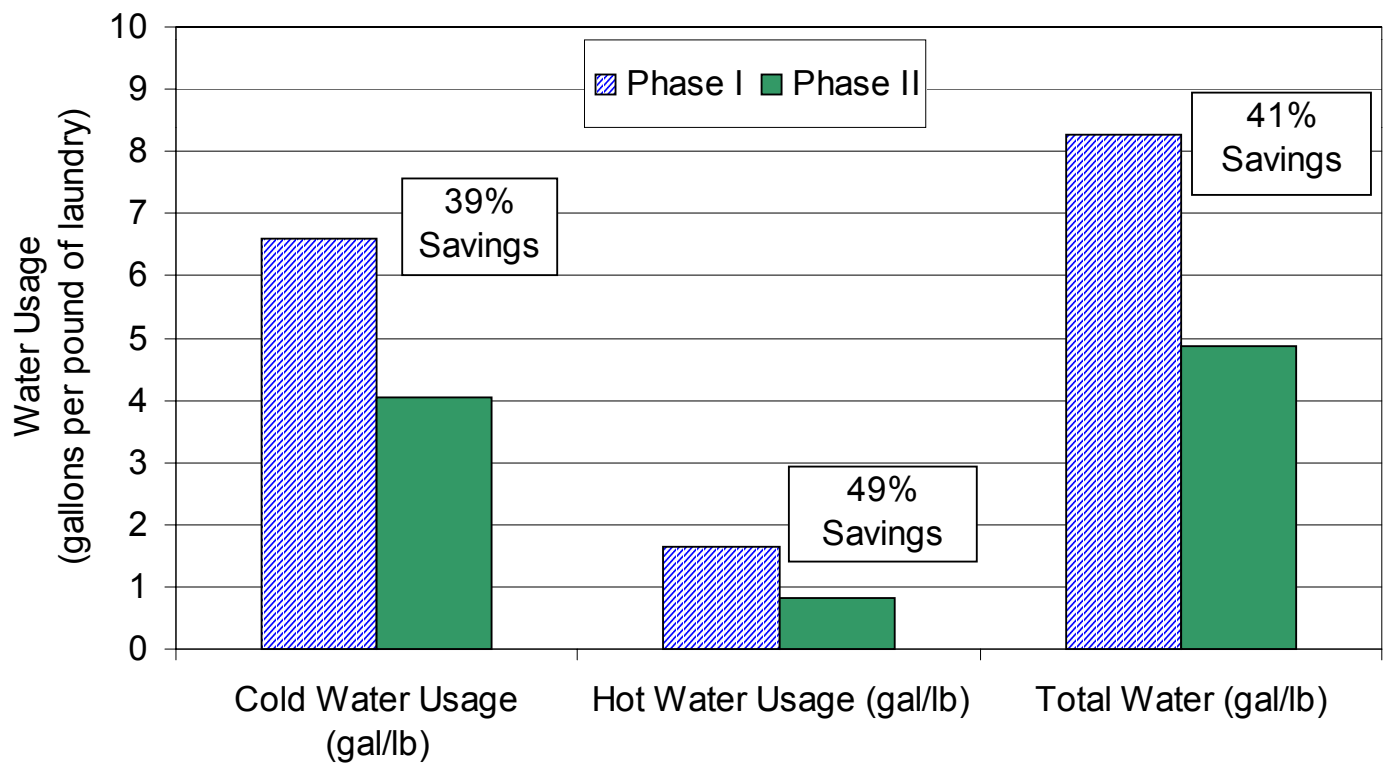

Figure 3.4 Water Consumption

In phase I, 66,807 gallons of water were consumed to wash 8,087 pounds of laundry in 1,695 loads. This yields specific water consumptions of 8.26 gallons/pound and 39.4 gallons/load. In phase II, 32,044 gallons of water were consumed to wash 6,565 pounds of laundry in 1,214 loads. Phase II specific water consumptions are 4.88 gallons/pound and 26.3 gallons/load. The total water savings are 13.1 gallons/load and, as Figure 3.4 shows, a $41 \%$ savings in water based on weight of laundry. Hot water savings were $49 \%$, and since most of the energy consumed by a clothes washer is due to the energy to produce hot water, one would expect the energy savings to be on this order. 


\subsection{ENERGY CONSUMPTION}

\subsubsection{WASHER ENERGY}

Washers consume energy through two main mechanisms: first is thermal energy in the hot water used by the washer, and second, is electrical energy to operate the motor and controls. Heat energy in the hot water used was calculated from the difference in the temperature of the hot and cold water supply to the washer and the volume of hot water used. We based our calculations on the energy needed to heat the water at $100 \%$ efficiency, and this gives a conservative figure for energy savings by reduced hot water use. Based on the fact that boilers are used to produce all of the hot water for the Summit Terrace Condominiums, energy savings through reduced hot water consumption would be somewhat greater than the savings in hot water energy.

The hot and cold water temperatures were measured by running hot and cold water over a calibrated thermometer at the kitchen sink. This was done on two separate visits to each condominium unit over the course of the study. Temperature data from these measurements is shown in Appendix D. The amount of hot water consumed was measured using the water meters described earlier. The energy contained in the hot water was determined for each load by the product of the hot water consumed by the washer and the temperature difference determined earlier. The specific heat of the water and appropriate conversion factors were used to change the energy results into $\mathrm{kWh}$ units. The electrical energy consumption of the washers was determined by one of two methods: (1) through prior knowledge of the machine energy consumption from existing databases, or (2) by direct measurement of the electric energy used under typical load conditions using the energy meters that were installed as part of the BWS. The fact that many of the phase I washers were identical simplified this task. When direct measurements of washer electrical energy consumption were needed, we worked with participants as needed to gather these data from energy meter readings.

Figure 3.5 shows both components of the washer energy consumption in units of $\mathrm{kWh}$ per pound of laundry for both phases of the Study. It is notable that there was energy efficiency improvement in both areas: reduced thermal energy through lowered hot water consumption, and reduced electrical energy consumption by the washer itself with use of electronic controls and a high-efficiency, switched reluctance motor drive. The combination provided a 50\% reduction in overall energy consumption by the washer. Figure 3.5 also makes it clear that future technologies that produce further hot water savings would provide a greater opportunity for reductions in overall energy consumption than would machine efficiency improvements. 


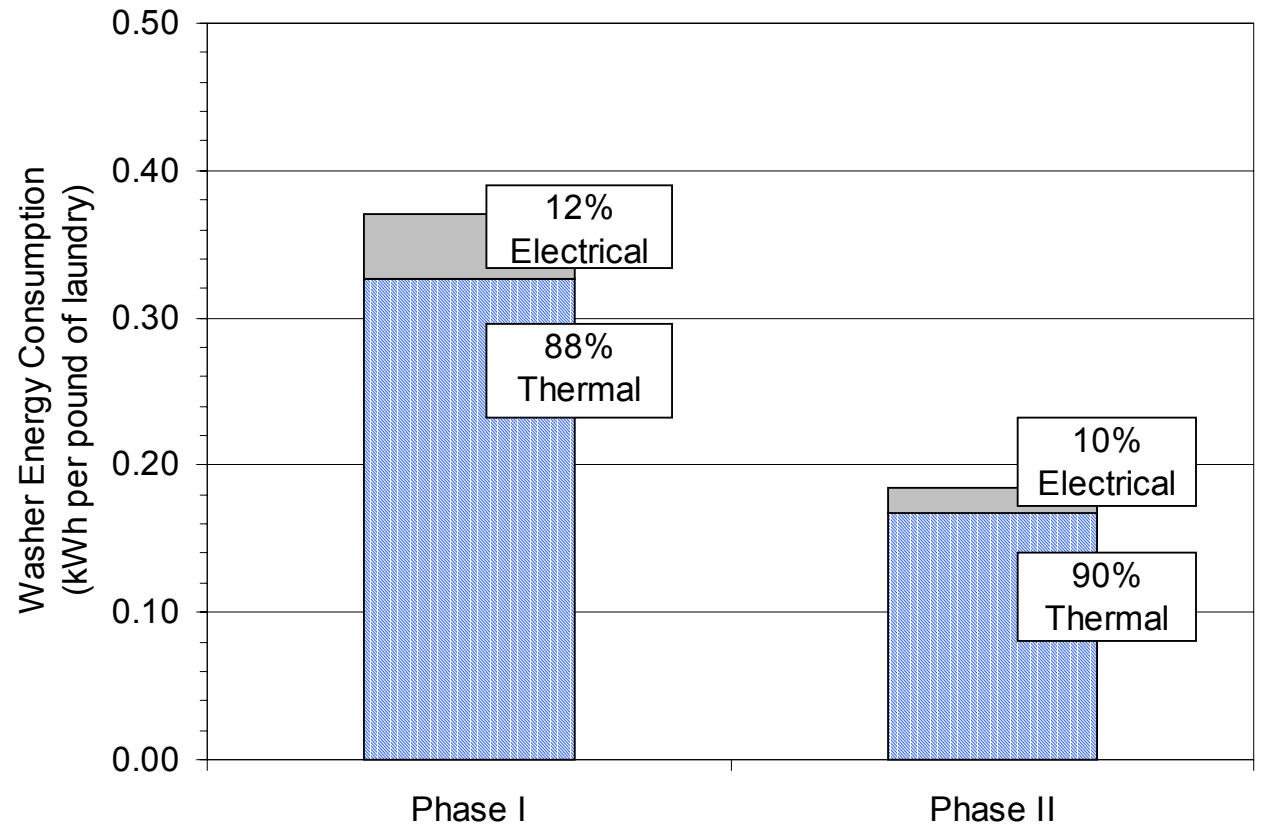

Figure 3.5 Washer Energy Consumption

\subsubsection{DRYER ENERGY}

All of the dryers in the condominium complex are electric. Electric dryers consume energy in three ways: first, a fan to blow air, second an electrical element to heat the air, and third, a motor to tumble the dryer drum allowing the hot air to come in contact with all parts of the clothing and to dry them by thermal evaporation of moisture. The energy consumption of a dryer depends on its cycle time, and the cycle time depends primarily on the amount of moisture present in the load when it is removed from the washer and placed into the dryer. The amount of moisture contained in a load is characterized by the remaining moisture content, or $\mathrm{RMC}$ which is a nondimensional number defined as the weight of moisture in the load divided by the bone dry weight of the load or,

$$
\mathrm{RMC}=(\text { wet weight }- \text { dry weight }) /(\text { dry weight }) .
$$

In the strict sense, an RMC equal to zero implies that the clothing contains no moisture; however, all materials - even ones that we consider dry - contain some moisture that is absorbed and is in equilibrium with moisture in the surrounding air. Typically, the equilibrium moisture content for "dry" clothing is $4-6 \%$ depending on the type of material. Typical RMCs for damp loads just removed from a washer might be $60-80 \%$ or higher depending on the type of load. For damp loads of a given size to tossed into a dryer, the lower the entering RMC, the less moisture there is to be evaporated and the shorter the drying cycle. The final spin speed and diameter of the tub of the washer determine the RMC of the damp load. Consequently, the performance of the washer has an indirect effect on the length of the drying cycle and the energy consumption of the dryer. 
After each load of laundry, BWS participants recorded information from the digital display on the energy meter that was attached to the electrical connections of the dryer. The difference between that reading and the reading from the previous dryer cycle was the energy consumed by the dryer for that load. Occasionally, a participant would inadvertently reset the meter or use the wrong scale. Problems like this were spotted by plotting cumulative energy consumption data and looking for data inconsistencies; data were corrected as necessary. From the data provided by the participants, the amount of energy consumed by the dryer per pound of laundry was determined. Figure 3.6 shows the dryer and washer energy savings between phases I and II of the study. Overall dryer energy savings were $22 \%$ and washer energy savings were $50 \%$ as shown. On average,

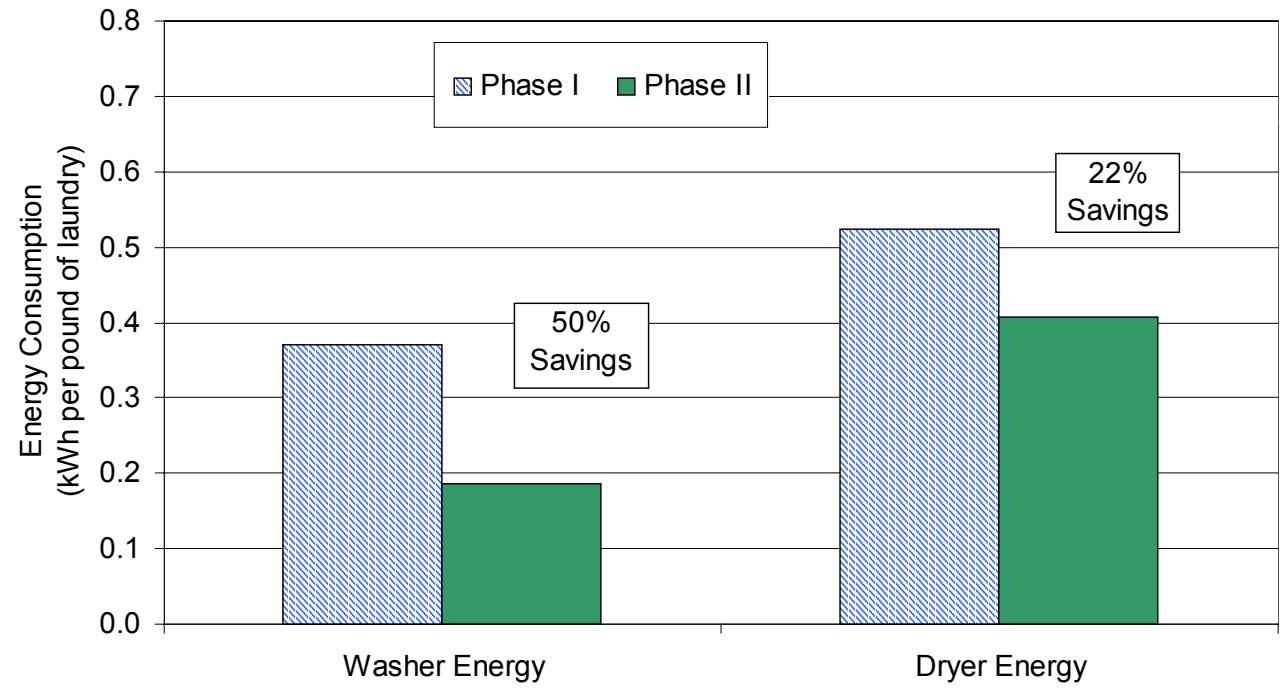

Figure 3.6 Washer and Dryer Energy Consumption

the RMC was reduced by $20 \%$ - in line with the $22 \%$ drop in dryer energy consumption. Notable is the fact that for both phases of the BWS, the dryers used more energy that did the washers

\subsection{DETERGENT USE}

Detergent use is an important item to study because of the impact of detergent concentration in wastewater that must be treated by municipalities and communities. Consequently, detergent use and patterns were monitored during the study. Each participant received a measuring cup marked in $1 / 4$ increments up to 2 cups. Before each load of laundry, the participant measured and recorded the amount and type of detergent they used.

Tumble-action (horizontal axis) washers produce a high degree of agitation that may lead to oversudsing if high levels of conventional detergents are used. Oversudsing can be minimized in several ways including (1) use of a low-sudsing detergent or one developed specifically for h-axis washers, (2) use of just enough conventional detergent to do the job without falloff in cleaning performance, and/or (3) washer sensor technology which is present in the phase II h-axis washers to detect oversudsing and to change cycle 
parameters accordingly. During phase I of the project, the participants used their conventional detergent. During phase II, participants had the option of using Tide (HE) a low-sudsing detergent developed especially for h-axis washers. Of all participants in phase II of the study, $19 \%$ chose to continue with their conventional detergent to which they were accustomed, while $81 \%$ changed to the Tide HE.

The amount of detergent used by the participants varied depending on the size of the load, type of clothing, and stain removal requirements. Figure 3.7 shows the fraction of loads using detergent amounts from $1 / 4$ cup to 2 cups. The distribution of detergent

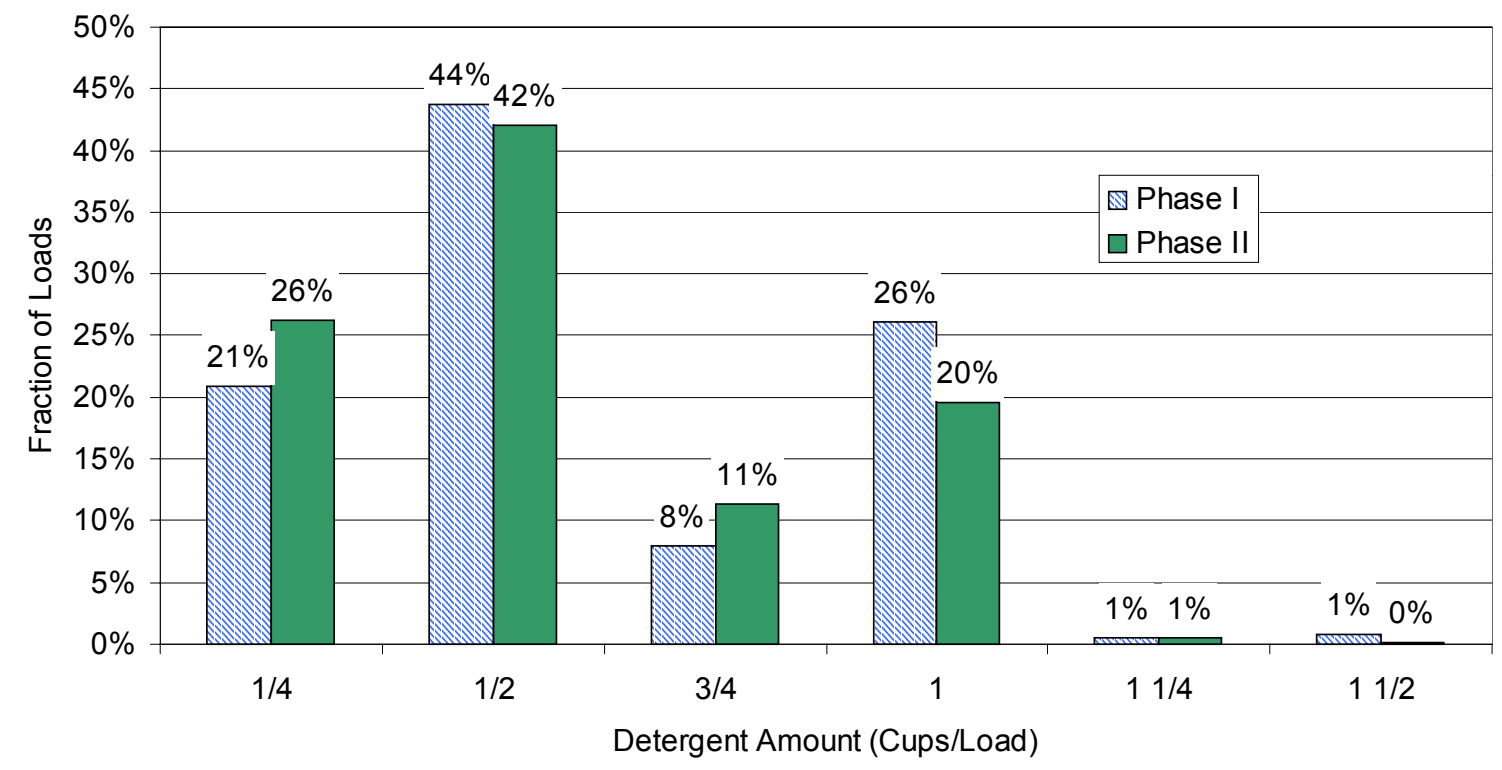

Figure 3.7 Detergent Use in BWS

concentration in loads changed somewhat between phases I and II. In phase I, 36\% of all loads used $3 / 4$ or more cups of detergent compared to $32 \%$ of all phase II loads. Moreover, in phase I, $80 \%$ of all loads used $1 / 2$ or more cups of detergent as compared to $74 \%$ of all phase II loads. This suggests an overall detergent savings in phase II, and the study showed an $8 \%$ overall savings in detergent per load. Since the average load weight was larger in phase II than in phase I, the BWS showed a $20 \%$ savings based on load weight as shown in Figure 3.8. 


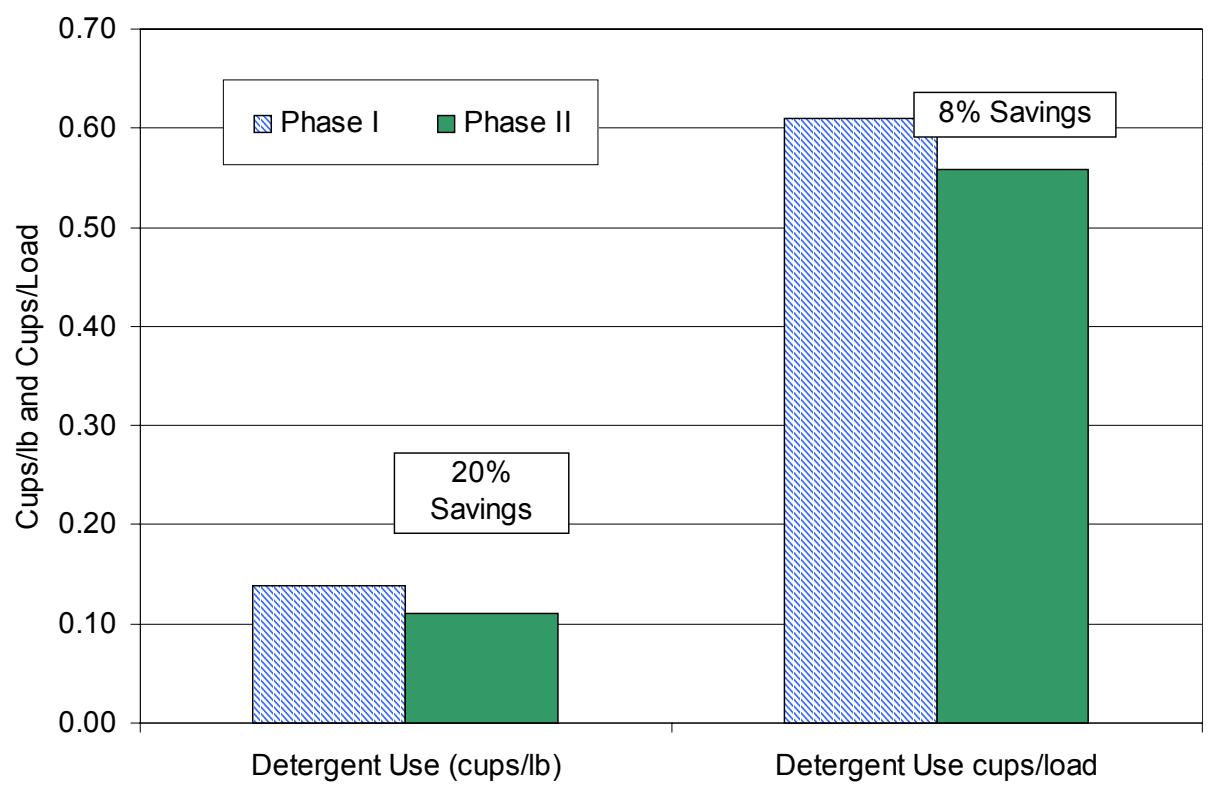

Figure 3.8. Detergent Use

\subsection{IMPACTS ON LAUNDRY HABITS}

To determine if the high-efficiency washing machine affected the participants' schedule for washing, we analyzed and compared schedule changes from phases I and II. Figure 3.9 shows that Monday and Saturday were big washdays with little variation between phases. Fewer loads were washed Tuesday through Friday, but not by a large margin.

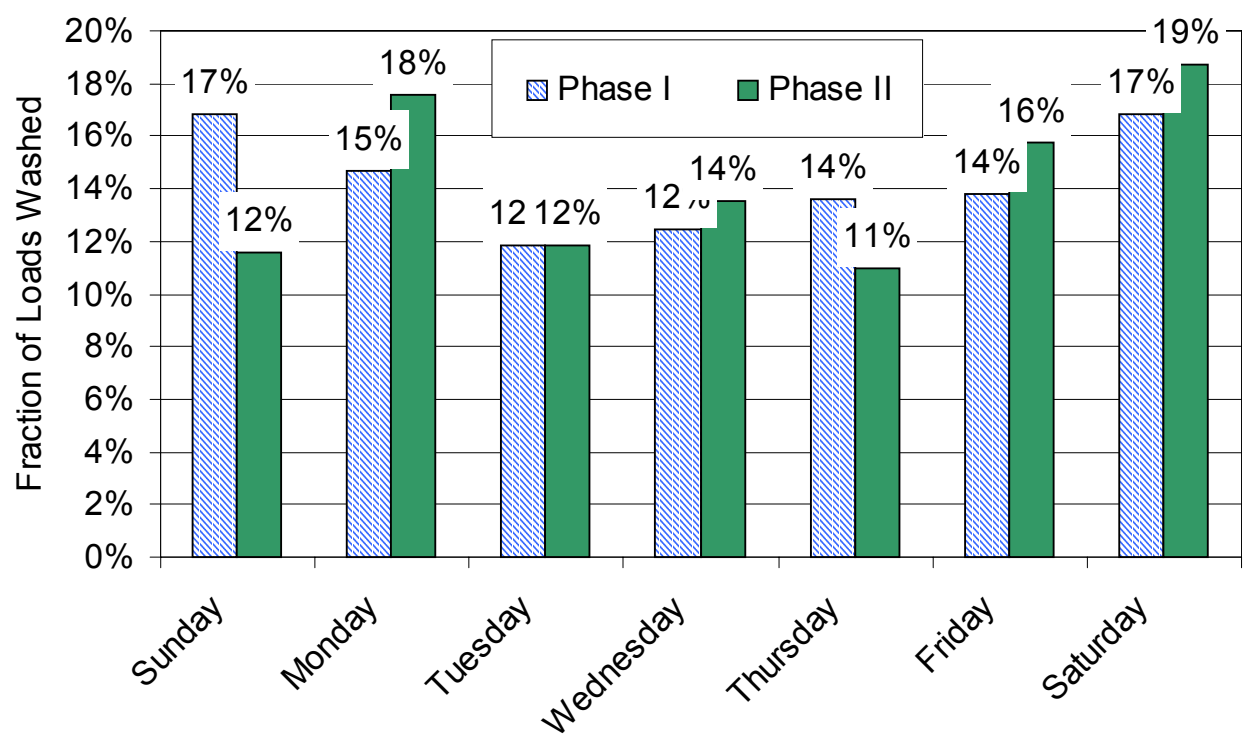

Figure 3.9. Wash Day Frequency 
Almost $50 \%$ of the loads were washed between $6 \mathrm{AM}$ and noon with about half that amount from noon to $6 \mathrm{PM}$ and similarly from $6 \mathrm{PM}$ to midnight as displayed in Figure 3.10. The time of day when loads were washed did not vary much from phase I to phase II.

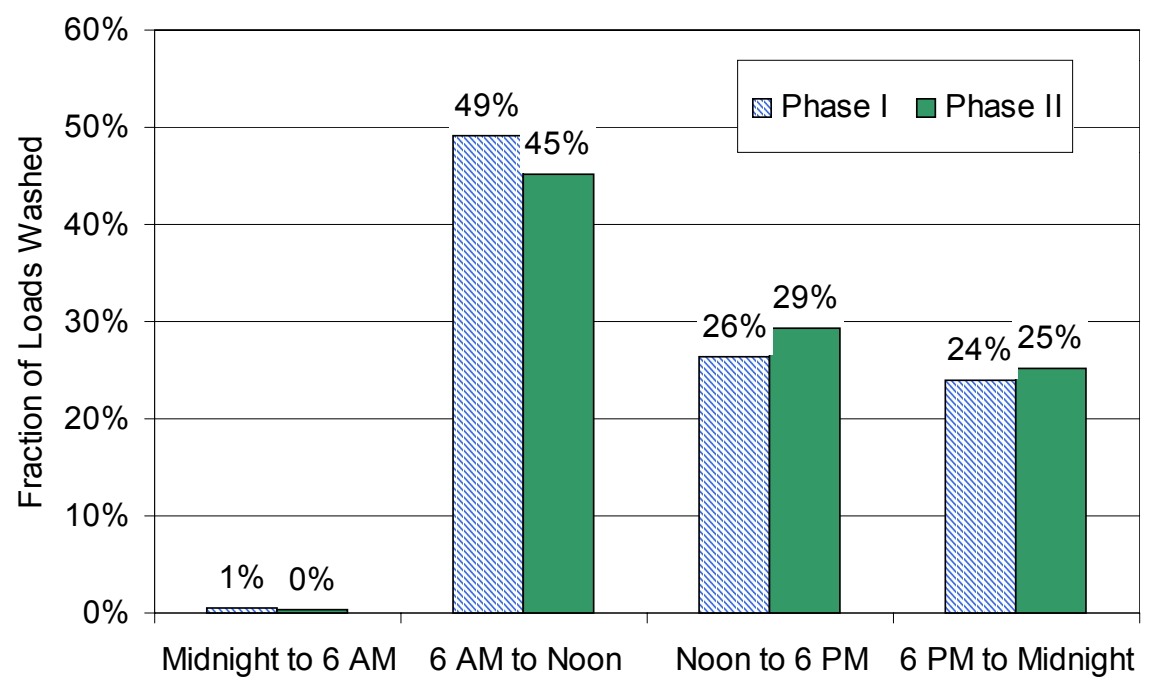

Figure 3.10. Wash Time during Day

\subsection{IMPACTS ON WASHER SETTINGS}

Participants recorded washer wash and rinse temperature settings for each load of laundry in both phases of the study. Figure 3.11 shows the comparison between the fractions of loads washed in cold, warm, and hot water. Phase II saw an increase in loads washed with warm and hot water settings. Similar data for the rinse cycle are shown in Figure 3.12. The fraction of loads rinsed in cold water increased by $5.5 \%$ from phase I to phase II. For both phases of the study, the fraction of cold water rinses were relatively close to the assumption used in the DOE Test Procedure that $82 \%$ of all rinses would be cold. ${ }^{6}$. Overall, the changes in wash/rinse settings between phases I and II were relatively minor and tend to suggest little change in how participants selected wash and rinse temperature settings due to the changeover to the $\mathrm{h}$-axis washer. 

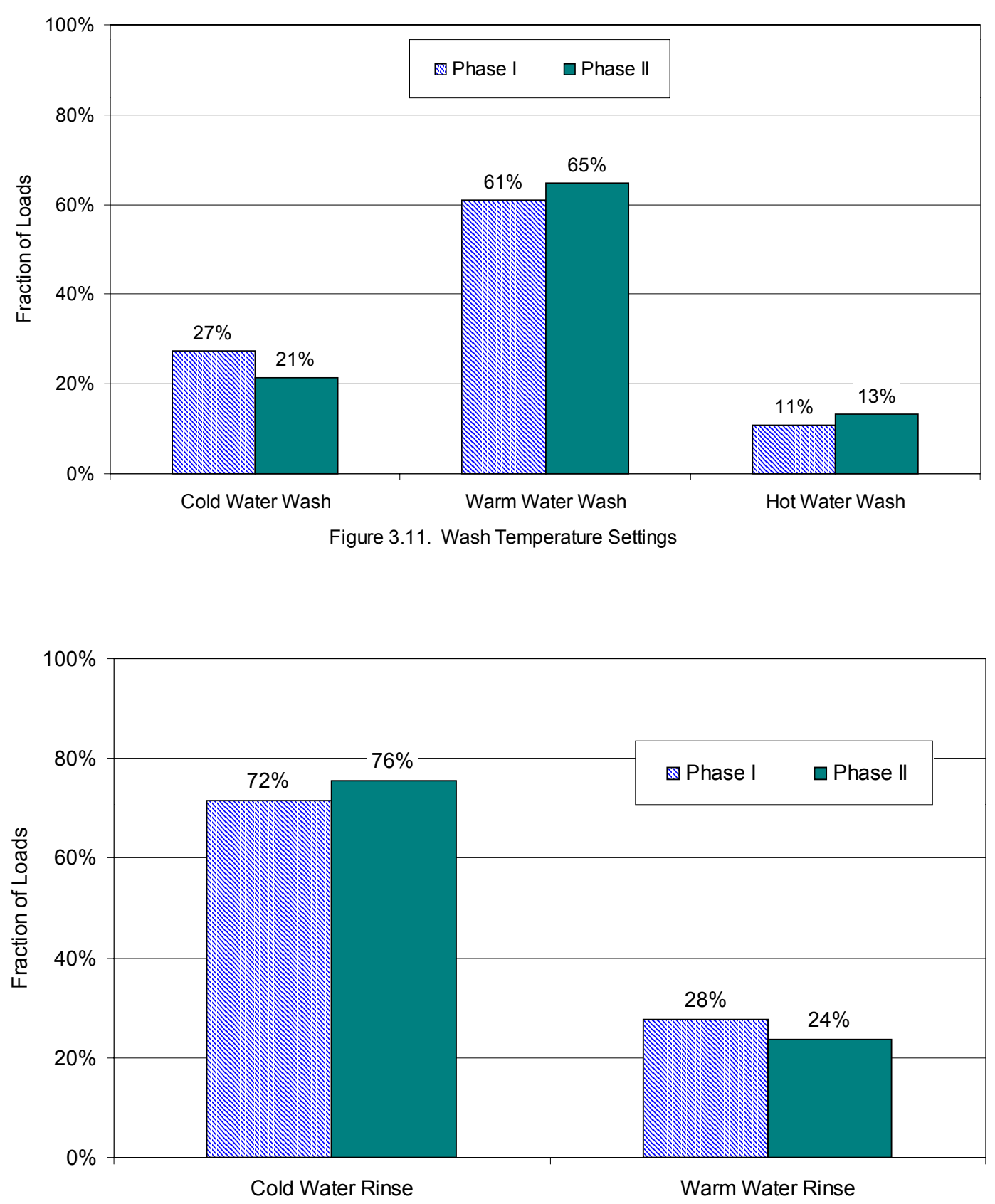

Figure 3.12. Rinse Temperature Settings

\subsection{CLEANING PERFORMANCE}

From a customer's perspective, cleaning performance of a clothes washer is a prime attribute. Energy saving features are not important enough to sacrifice cleanliness, therefore, cleanliness of the participants' clothing is of utmost importance and a requirement of any washing machine. In the BWS, cleaning performance was evaluated by participants based on visual inspection of each laundry load removed from the dryer. The participants' evaluations of the cleanliness is important and was attainable due to the length of the study. The project's 5-month duration over two phases made it likely that a 
participant would wash the same articles of clothing a number of times and would be aware of any noticeable changes in cleaning performance.

Participants were requested to indicate, for each load of laundry, their satisfaction with the cleaning performance of the machine on a scale of five choices ranging from "Completely satisfied" to "Not at all satisfied", as seen in Figure 3.13. Numerical

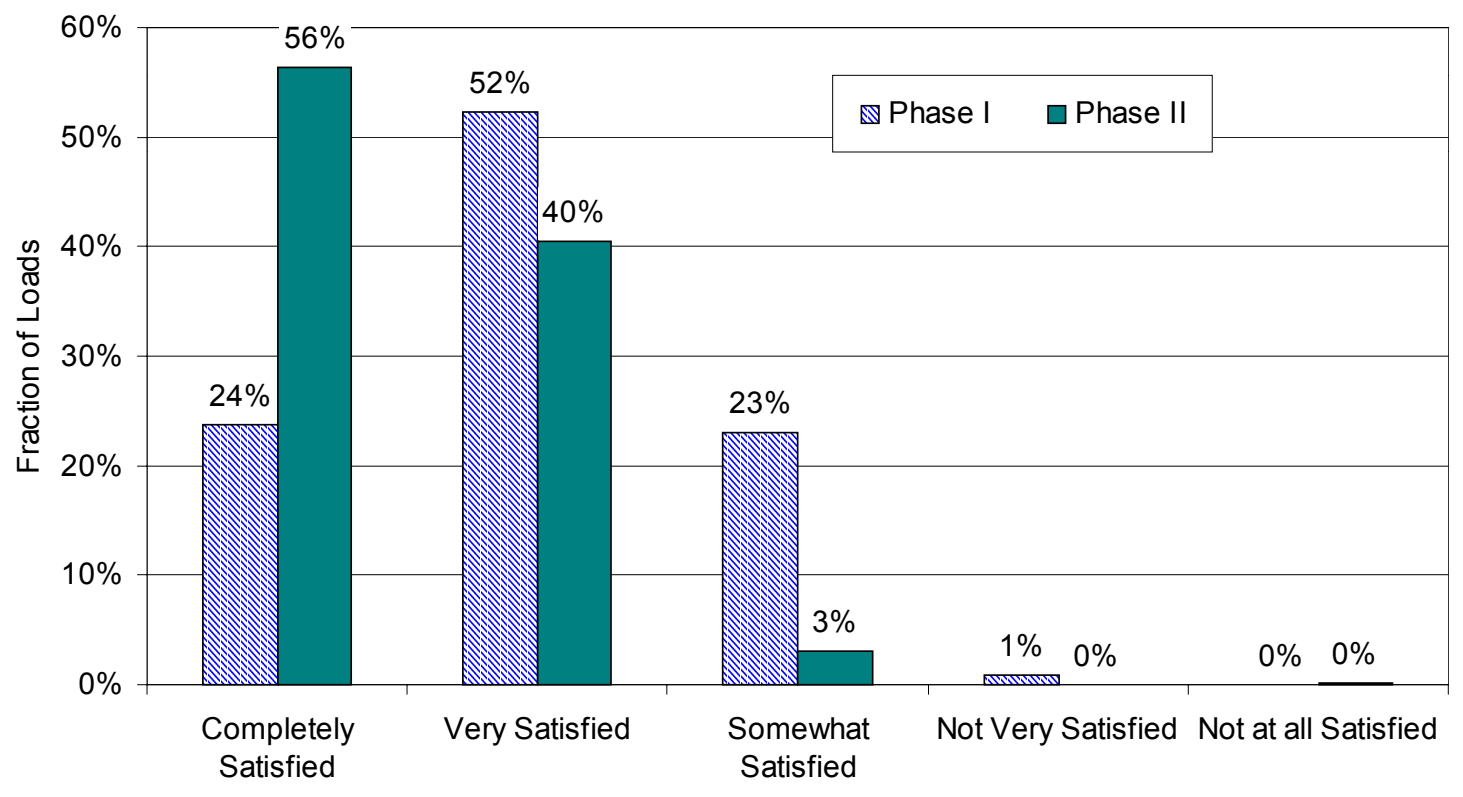

Figure 3.13. Satisfaction with Cleanliness

assignments were made for these choices with 5 representing "completely satisfied" and 1 representing "not at all satisfied." The majority of responses indicated that the participants were pleased with the cleaning ability in both phases, however, there was a noticeable difference in the degree of satisfaction between phases. The fraction of loads with which participants were "very" to "completely" satisfied increased from 76 to 96 percent, with the "completely satisfied" range more than doubling. In addition, the fraction of loads in which participants were "somewhat satisfied" decreased from $23 \%$ to $3 \%$ indicating an overall satisfaction improvement. Figure 3.14 shows the overall satisfaction level between phase I and phase II, indicating a 14\% overall improvement based on the arbitrary numerical scale chosen. 


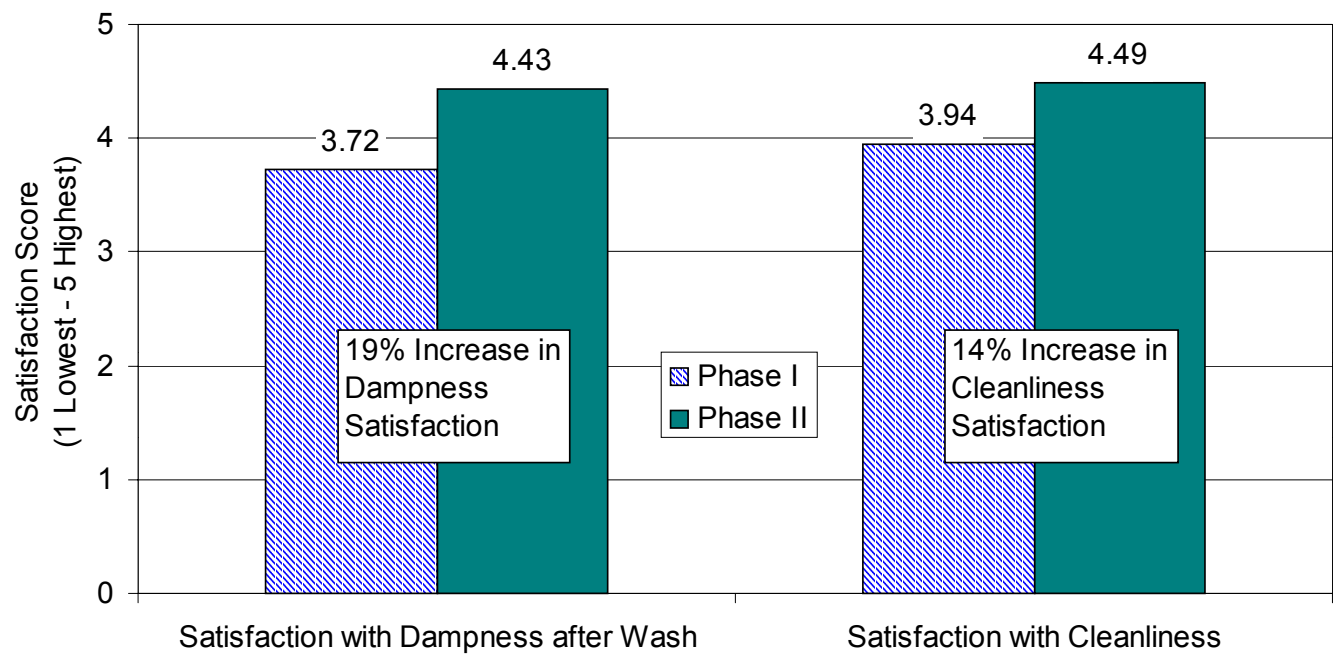

Figure 3.14. Dampness and Cleanliness Satisfaction Scores

\subsection{IMPACTS ON LOAD DAMPNESS}

Participants were asked to indicate how satisfied they were with how dry the loads felt as they were removed from the washer. A rating of "not at all satisfied" would mean that at the end of the wash cycle, the load was much wetter than anticipated, indicating that the spin cycle was not as effective as participants believed it should have been. The drier the clothing removed from the water, the less energy and time the dryer will use to fully dry the clothes, thereby reducing dryer energy consumption. Dampness satisfaction ratings improved significantly from phase I to II. Ratings of "very satisfied" to "completely satisfied" increased from $58 \%$ to $96 \%$, with the "completely satisfied" range almost tripling as shown in Figure 3.15. In addition, the fraction of loads in which participants were "somewhat satisfied" decreased from $36 \%$ to $4 \%$, indicating an overall satisfaction improvement. Figure 3.14 shows the overall satisfaction level between phase I and phase II, indicating a $19 \%$ overall improvement in the dampness satisfaction level. As for the cleaning performance, a 5-point scale was used to make this determination.

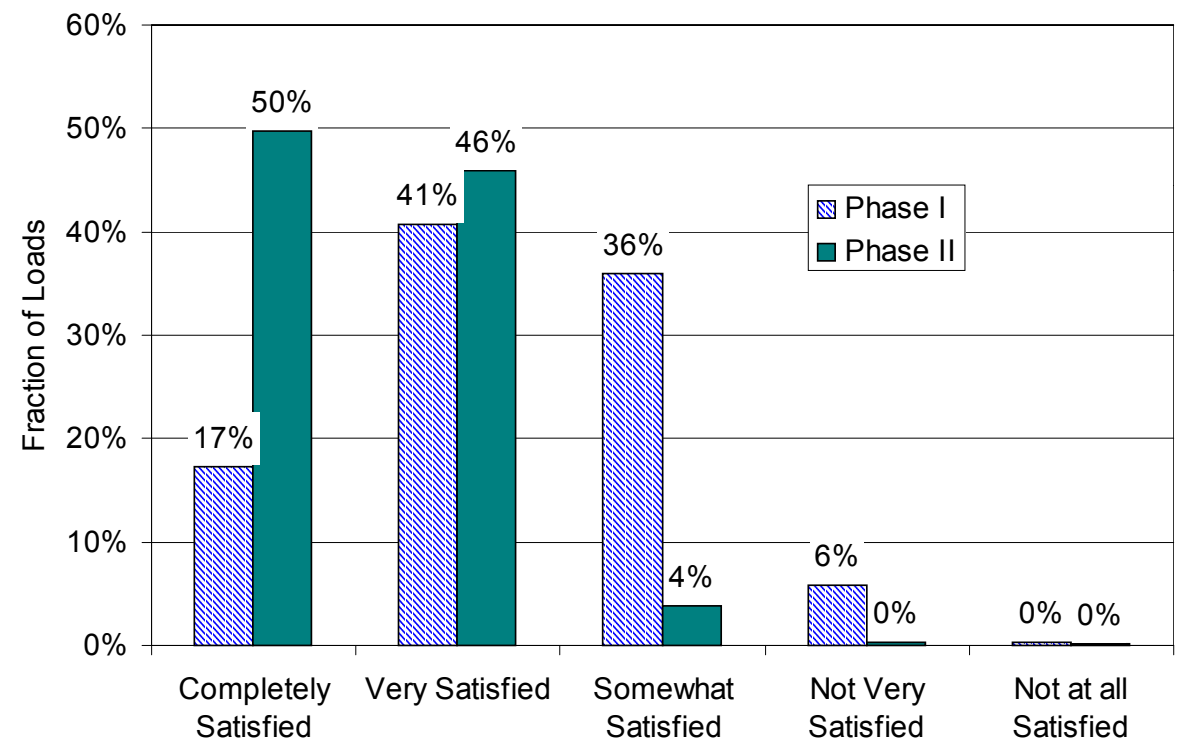

Figure 3.15. Dampness After Wash Satisfaction 



\section{ANALYSIS OF FINDINGS AND IMPACTS}

A principal difference between the BWS and prior field studies of washer performance was an evaluation of the washer's impact on dryer energy consumption. Field measurements of energy use during the BWS showed that the energy consumption of the washer (including the thermal energy in the hot water used) is much less than the energy consumption of the dryer as was shown in Figure 3.6. In Phase I, dryer energy consumption was $40 \%$ more than washer energy consumption, and in Phase II, the dryers consumed $115 \%$ more energy than did the washers. However, the average energy consumption of both washers and dryers $(\mathrm{kWh} /$ pound of laundry) in phase II was much less than in phase I.

We would assume that the dryer's energy consumption is largely due to the moisture that must be evaporatively removed from the clothing, so that loads with lower RMC leaving the washer would dry more quickly and therefore require less dryer energy. This observation suggests that high efficiency washers with high-speed final spins would be particularly beneficial in reducing the overall energy used on the laundry process. In the BWS, we examined several issues associated with the impact of the washer's performance during its final spin on dryer energy consumption including:

- What variables account for most of the dryer energy savings?

- How does the spin cycle affect the RMC and dryer energy consumption?

- What are the performance metrics for clothes washers and how did the h-axis design perform in the field against these metrics?

In the following sections, we investigate these questions.

\subsection{DRYER ENERGY SAVINGS}

The displays of energy meters attached to each dryer were read and recorded by the study participants for each load of laundry. The difference in two readings for successive loads gave the dryer energy consumption for each load. The average dryer energy consumption was determined for loads that fell into 2-pound weight bins for both phases of the study. As shown in Figure 4.1, average dryer energy consumption generally increased with load weight as expected. 


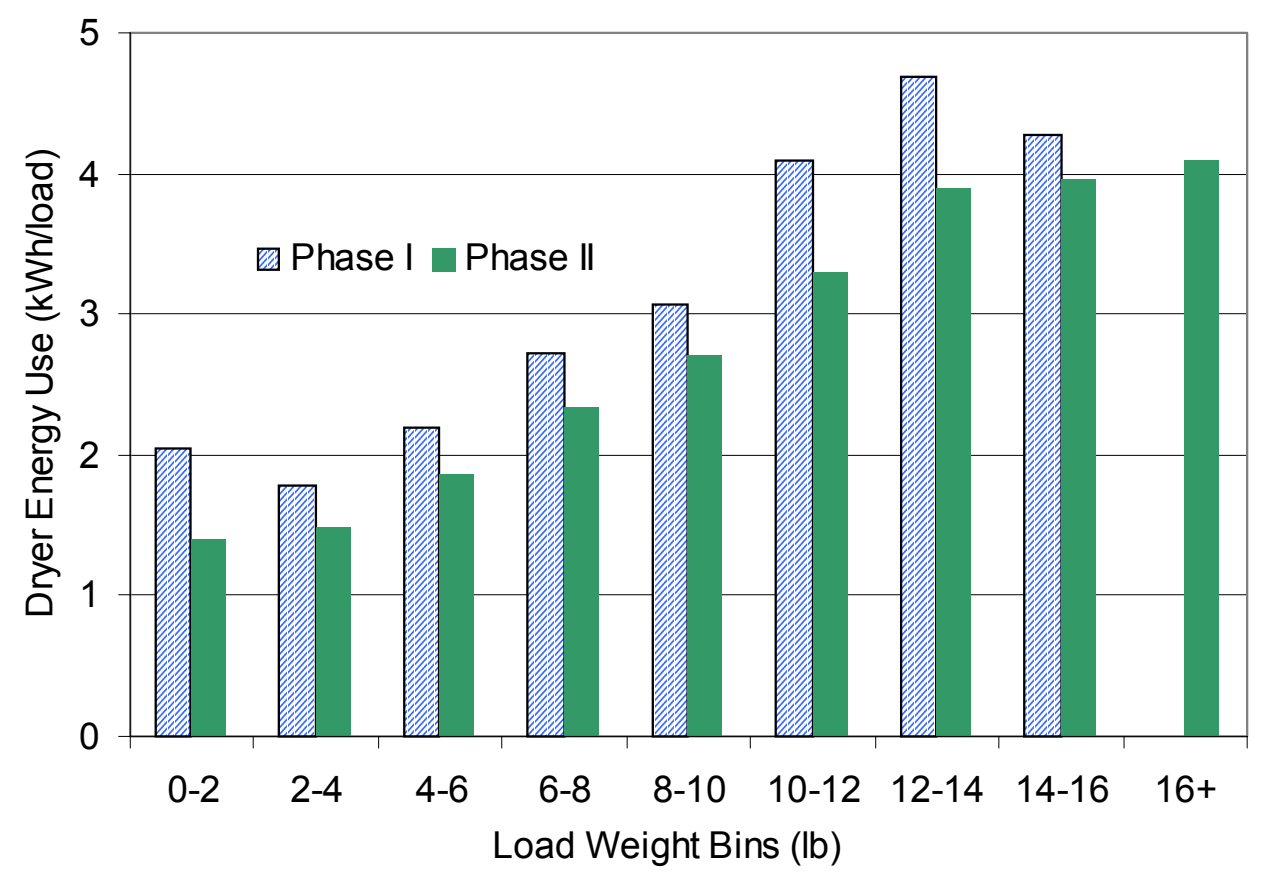

Figure 4.1. Dryer Energy Consumption by Load Weight Distribution - All Loads

The variations from the general trend of increasing energy consumption with increasing load weight may be accounted for by small sample size: only $2 \%$ of all phase I loads weighed between zero and two pounds, and less than 1\% weighed between 14 and 16 pounds. The phase II data with all participants using the same model washer and, in most cases, the same model dryer are more consistent. Figure 4.1 indicates that in the midrange of load weights, dryer energy consumption increases at a rate of $0.3 \mathrm{kWh}$ per pound (prewash) of laundry.

\subsection{REMAINING MOISTURE CONTENT AND DRYER ENERGY USE}

We turn now to an examination of the performance of the washer's final spin speed in removing moisture from loads in both phases of the study. As mentioned, the effectiveness of mechanically removing moisture from a load is characterized by the remaining moisture content, or RMC. During a drying cycle, there are three opportunities for weighing loads: (1) before drying the damp clothes, (2) at the end of the drying cycle, and (3) at the end of a deep drying cycle to return clothes to a "bone-dry" condition as called for in the test procedures for determining the actual RMC, or RMCa. These opportunities are shown in the sketch below.

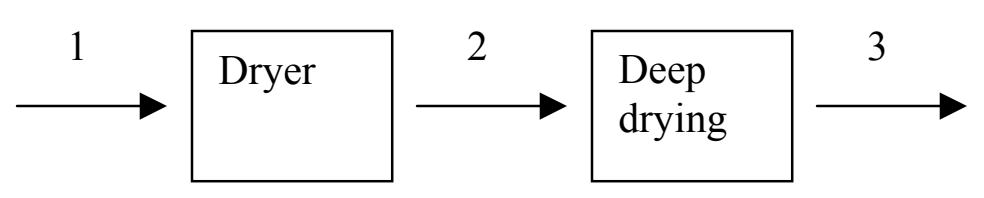


Having just been removed from the dryer, loads at point " 2 " will weigh less than at point " 1 " but more than at point 3 . There are several ways that RMC can be defined based on these three weights. The first is initial RMC defined as,

$$
\mathrm{RMCi}=(\mathrm{W} 2-\mathrm{W} 3) / \mathrm{W} 3 .
$$

Here, W2 is the load weight at point 2, and W3 is the load bone-dry weight at point 3. RMCi characterizes the moisture that is in the load after it is dried but not to a bone-dry condition. If we assume that the load from the dryer is bone-dry, the RMCi would be zero. However, clothes are usually removed from the dryer before reaching that condition, and RMCi is greater than zero. A second RMC definition is the fieldmeasured RMC or RMCf defined as,

$$
\mathrm{RMCf}=(\mathrm{W} 1-\mathrm{W} 2) / \mathrm{W} 2 .
$$

Equation (2) is the technique followed for the BWS. It required that participants weigh loads before and after the drying cycle. This was simple to implement and accounted for all clothes dried. Based on experience, we anticipated that RMCf values would be in the range of 0.5 to 1.5 or more depending on the type of load and its level of moisture before being tossed into the dryer. Finally, there is an RMCa or "actual" RMC that can be defined between conditions 1 and 3 across a dryer that can take a load to bone dry conditions. In this case,

$$
\mathrm{RMCa}=(\mathrm{W} 1-\mathrm{W} 3) / \mathrm{W} 3 .
$$

Since W3 will always be the smallest of the three weights for any load, RMCa will always be positive. Moreover, the definition of RMCa is the definition of the RMC that would be measured in the laboratory. Laboratory tests to determine the moisture content in a load are based on bone-dry final conditions.

To understand the impact of entering dampness levels on measured values of RMC, we solved equations (1), (2) and (3) simultaneously and generated the relation shown in Figure 4.2. The ordinate is the ratio of actual to field-measured RMC. If RMCi $=0$ (i.e. the loads tossed into the dryer are later removed in bone-dry condition, there would be no difference between RMCf and RMCa irrespective of any field-measured value of RMCf. If a load is dried to a typical level of moisture content $\mathrm{RMCi}>0$, the ratio $\mathrm{RMCa} / \mathrm{RMCf}$ is larger than one, and the exact ratio depends on RMCf as shown. Typical levels of $\mathrm{RMCi}$ are $4-6 \%$, and this indicates that the ratio $\mathrm{RMCa} / \mathrm{RMCf}$ is about 1.1 (i.e. the actual $\mathrm{RMC}$ is $10 \%$ higher than what would be measured in the field). This is reasonable due to fact that RMC values measured in the laboratory are based on bone-dry weights. 


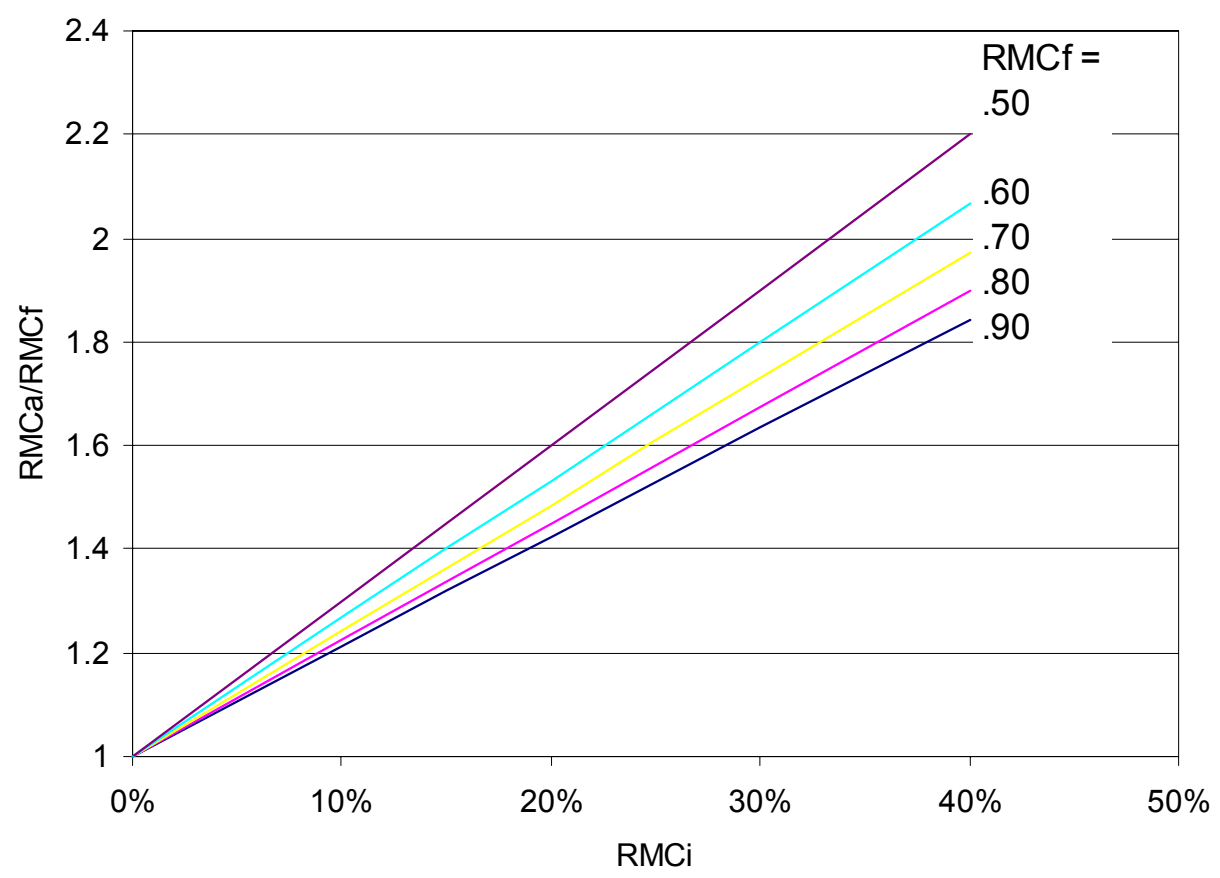

Figure 4.2. Impact of Initial Load Moisture on RMC Determinations.

Figure 4.3 shows measured RMCf data from the study for loads binned in 2-pound load sizes. In phase I, the RMCf was between 0.7 and 0.8 for typical load weights. The data show that with increasing phase I load weights, the RMCf tends to drop by about $10-15 \%$ - an improvement in moisture extraction. There is apparently some benefit to be had in larger loads since there are enough layers of away from the inside wall of the wash tub so that they are able to compress the clothes next to wall of the tub for better overall water

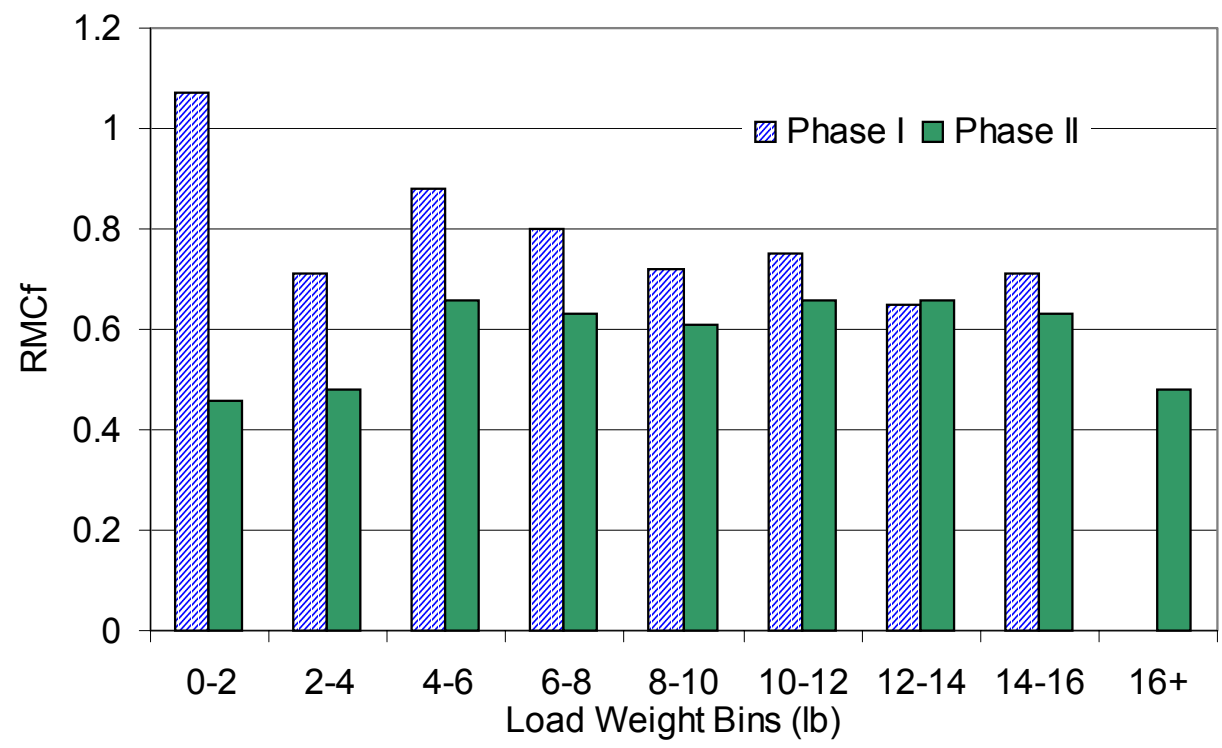

Figure 4.3. Remaining Moisture Content of Loads after Final Washer Spin by Load Weight Distribution - All Loads. 
removal during the final spin. The extraction of moisture was significantly greater for low load weights in phase II than in phase I. At higher load weights ( $>4$ pounds), the RMCf for phase II remained at about $60 \%$ and for the most part, was significantly lower than for phase I.

A principal reason for overall reductions in $\mathrm{RMCf}$ is due to a high final spin speed for the h-axis washer that provides improved water extraction. The final spin speed for the $h$ axis washer is $800 \mathrm{rpm}$ for normal loads and $1000 \mathrm{rpm}$ in the "max extract" setting.

These spins are 20 to $40 \%$ higher than the $600-700$ rpm speeds for the conventional phase I washers.

Changes and dryer energy consumption and RMCf between phases I and II are shown in Figure 4.4. The overall reduction in RMCf compared favorably with the $22 \%$ savings in

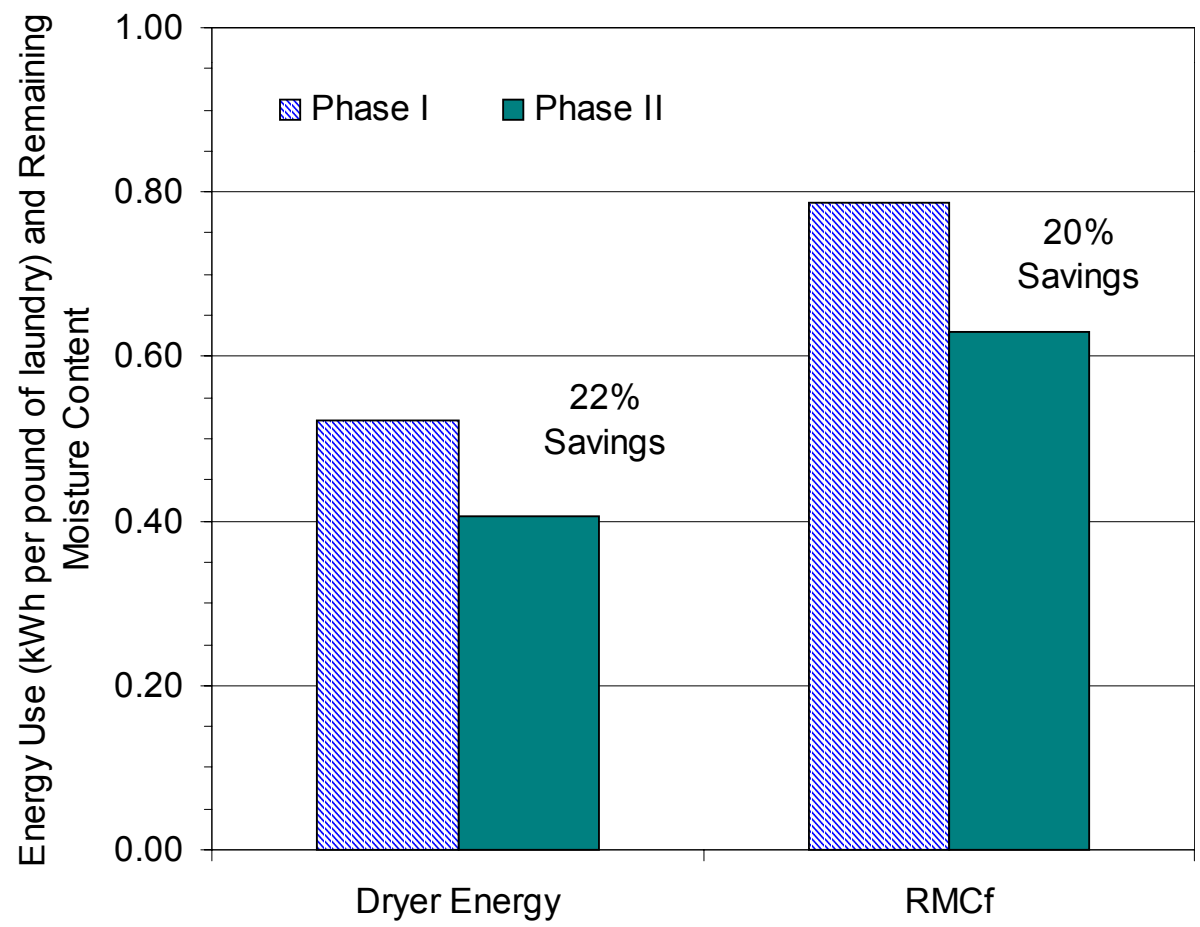

Figure 4.4. Dryer Energy Consumption and Remaining Moisture Content

dryer energy consumption as shown. This suggests a strong linkage in RMCf and dryer energy consumption. We tested this linkage by examining data from the entire study to determine the correlation between dryer energy consumption and RMCf. Due to the variability in load sizes, phase I washers and dryers as well as great variation in the types of loads washed by all of the study participants, the scatter was too high and the correlation in dryer energy consumption and RMCf was weak. We addressed this difficulty by selecting data from a single participant (participant " $A$ ") to study the linkage between dryer energy use and moisture content. With a single participant, variability in load characteristics and types would be reduced, and the problem from accommodating different phase I washers would be eliminated. Since a dryer removes moisture from 
clothes through evaporation, dryer energy consumption should be related to the weight of moisture removed during the drying process. From Eq. 2, this weight is (RMCf)(W1). From measurements of load weights and dryer energy consumption for each load, we plotted the relation shown in Figure 4.5. For both phases, the data showed a good

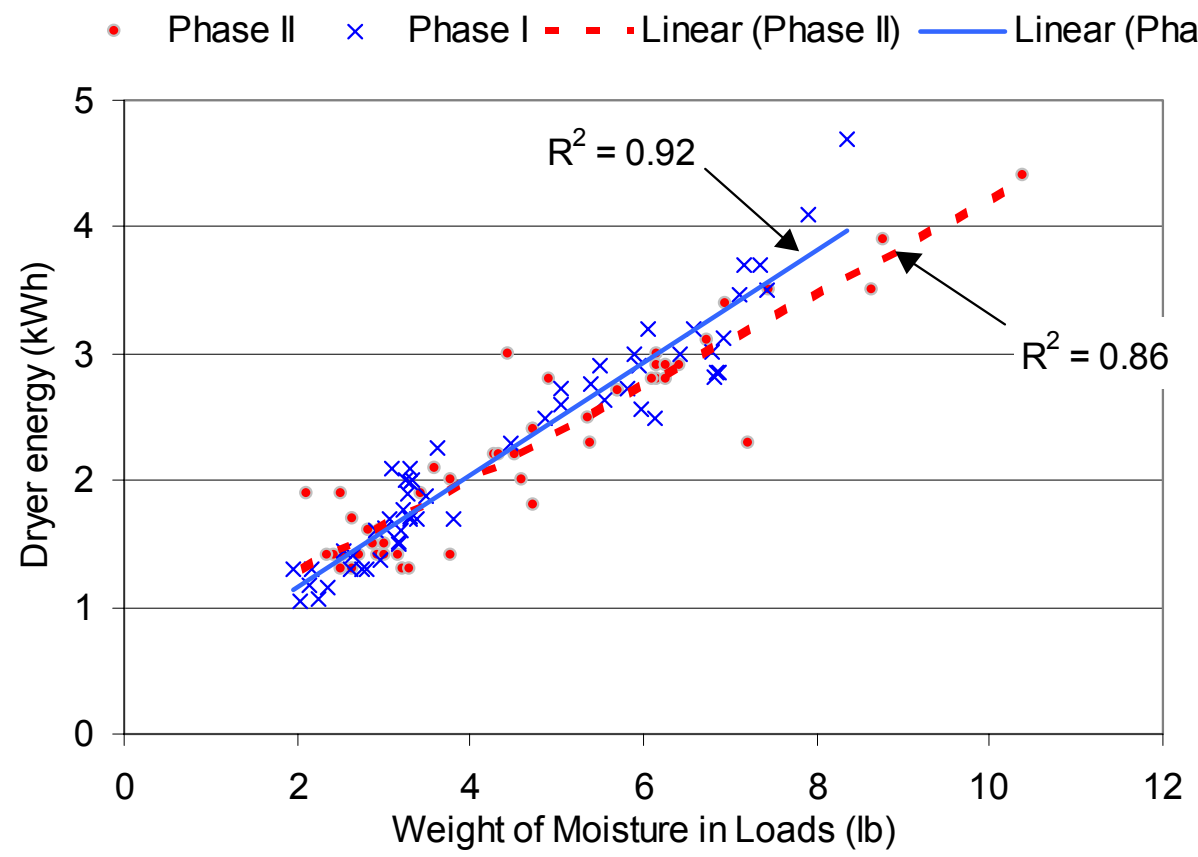

Figure 4.5. Impact of Dryer Energy Consumption on Load Moisture Content - Participant "A".

correlation between moisture weight removed by the dryer and dryer energy consumption. Most of the dryer energy consumption was explained by the removal of moisture from the loads as indicated by an adjusted R-squared of approximately 0.9. This was true across all load types including ones such as mixed cottons in which the moisture is tightly bound, and synthetic and permanent press articles that tend to dry more readily. The best trend to the phase I and II data appeared to be straight lines that showed a linear relation (least squares fit) between moisture removed and dryer energy consumption. The slopes of these lines are,

$0.44 \mathrm{kWh} / \mathrm{lb}$ moisture removed, phase I

$0.37 \mathrm{kWh} / \mathrm{lb}$ moisture removed, phase II.

Most of the dryer electrical energy is used to heat air that is used to evaporate moisture (surface and bound water) from the load of clothing. If we assumed that all of the moisture in a load were initially in a liquid phase, the theoretical amount of energy needed to change the water into the vapor phase would be $0.29 \mathrm{kWh} / \mathrm{lb}$ moisture - a limiting efficiency value for an evaporative dryer. 


\subsection{ENERGY FACTOR}

The efficiency of several major appliances including clothes washers is described by an Energy Factor. Depending on the appliance, the energy factor can be dimensionless or, as in the case of clothes washers, can have dimensions. The clothes washer energy factor is defined as the volume of the washing tub (in cubic feet) divided by the total electric and thermal energy used by the washer under a standard laboratory testing protocol. As in the case of all appliances for which an energy factor applies, the higher the energy factor, the more efficient the appliance. To be sold in the United States, standard washers manufactured before 2004 must have and EF of at least $1.18^{7}$. To account for the influence of the final spin speed of the washer on dryer energy consumption, a new efficiency metric, the modified energy factor or MEF was developed. Like the EF, the numerator of the MEF is the volume of the tub in cubic feet; however, the denominator of the MEF includes dryer energy consumption. Standard-sized clothes washers sold in the United States between 2004 and 2007 must possess a minimum MEF of 1.04. After 2007, washers must have an MEF of 1.26 or better.

The EF and MEF are metrics used to characterize the efficiency of clothes washers in the laboratory. Tests to determine values for the EF and MEF are done under carefully controlled laboratory conditions of water temperature and load characteristics (weight, entering moisture content, load makeup among others). Controlled conditions allow the performance of the full range of clothes washers to be determined on an equal footing. Performance results from tests done under these conditions are used to provide annual operating cost estimates that are placed on the EnergyGuide label, giving consumers information helpful in buying decisions.

Although field conditions in the BWS were not the same as those needed for performing EF or MEF determinations in the laboratory, the field data was sufficient to allow a determination of both $\mathrm{EF}$ (field) and MEF(field) for the phase II washers. From data, we determined that the EF(field) for the h-axis washer was 4.53 and the MEF for these washers was 1.21. If laboratory measurement corroborate these results, it is likely that the phase II h-axis washers would come very close to meeting the 2007 efficiency threshold for energy efficiency. 


\section{CONCLUSIONS}

The main target of the BWS was to identify the savings of water, washer energy, dryer energy, and other possible benefits of the h-axis washer over existing, conventional vertical axis washers in an urban setting. We found that loads washed with the existing, conventional washers required an average of 40 gallons of water for the washer and a total of $2.25 \mathrm{kWh}$ of energy (thermal and electrical) for the washer and dryer. By replacing the existing washers with the h-axis design, water consumption was reduced by $41 \%$ and energy consumption of the washer was reduced by $50 \%$. Moreover, dryer energy consumption fell by $22 \%$ due principally to the fact that the final spin of the new washer did a better job of extracting moisture from each load so that the dryer needed less energy. There were also savings in detergent volume as shown in the collective, overall results in Figure 5.1.

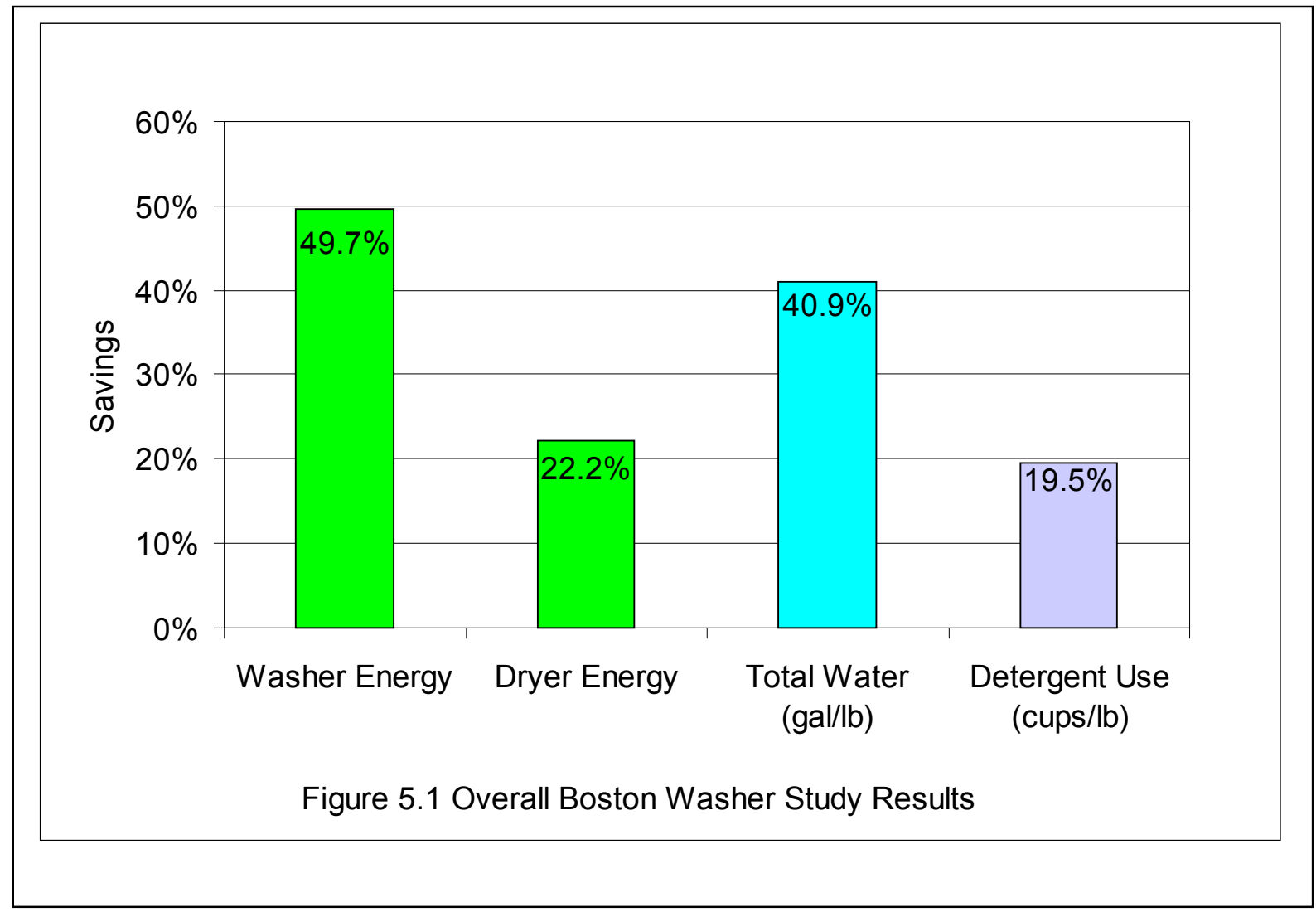

Households in the U.S. wash around 35 billion loads of laundry each year, and this consumes $2.6 \%$ of the total residential energy use. Full implementation of this technology in the U.S. has the potential to save around 40 billion kWh of end-use energy and 500 billion gallons of water annually. This is almost enough energy savings to power the entire city of New York for a year and enough water savings to equal 77 days of water flow over the American Niagara Falls ${ }^{8 \& 9}$. 
The impacts of the horizontal axis washer on the participants' laundry habits including time of day to wash, day of week to wash, wash settings, and rinse settings were found to change little, if at all.

The participants did see some positive changes with the high efficiency washer. Listed below are the changes, reasons for the change, and other possible outcomes resulting from these changes.

Table 2. Characteristics of Laundry Changes

\begin{tabular}{|l|l|l|}
\hline $\begin{array}{l}\text { Characteristic of } \\
\text { Laundry Load }\end{array}$ & Reasons for Change & Possible Outcomes \\
\hline $11 \%$ Larger Loads & Tub accessibility & $\begin{array}{l}\text { Fewer loads required, saving } \\
\text { time for participants }\end{array}$ \\
\hline $20 \%$ Detergent Savings & $\begin{array}{l}\text { Larger loads with the same } \\
\text { or less detergent use }\end{array}$ & $\begin{array}{l}\text { Potential cost reductions; } \\
\text { eases wastewater treatment } \\
\text { burden }\end{array}$ \\
\hline $20 \%$ Savings in RMC & $\begin{array}{l}\text { Better moisture extraction } \\
\text { with high speed final spin }\end{array}$ & $\begin{array}{l}\text { Reduces drying time and } \\
\text { energy consumption of dryer }\end{array}$ \\
\hline $\begin{array}{l}\text { Significant increase in } \\
\text { Cleanliness Satisfaction }\end{array}$ & $\begin{array}{l}\text { Possibilities: new machine; } \\
\text { probable better cleaning }\end{array}$ & $\begin{array}{l}\text { Less rewash; happier } \\
\text { customers }\end{array}$ \\
\hline $\begin{array}{l}\text { Significant increase in the } \\
\text { Satisfaction of Dampness } \\
\text { of clothing after Wash }\end{array}$ & $\begin{array}{l}\text { Improved moisture } \\
\text { extraction }\end{array}$ & $\begin{array}{l}\text { Reduces drying time and } \\
\text { energy consumption of dryer }\end{array}$ \\
\hline
\end{tabular}

In summary, the Boston Washer Study demonstrated and quantified the impact of a changeover to high efficiency washers in a urban setting. The study found significant improvements and savings in variables including: washer and dryer energy consumption, water consumption, detergent use, customer satisfaction, drying time, and higher average load weights for greater laundry throughput. 


\section{APPENDIX A. INSTRUMENTATION MODIFICATION}

\section{Water Meters}

The following information - details regarding the distributed water meters used in the Study - is provided to help water utilities and others who may be interested in conducting similar projects requiring end-use metering of water fixtures or appliances such as clothes washers. Described is the technique we used for adapting a conventional water meter with a remote digital readout that could be easily read by the participants with each load of laundry. This eliminated any need for the water meters to be viewable by the participants. The modification was found to be simple to implement, relatively inexpensive and retained the inherent accuracy of the water meter.

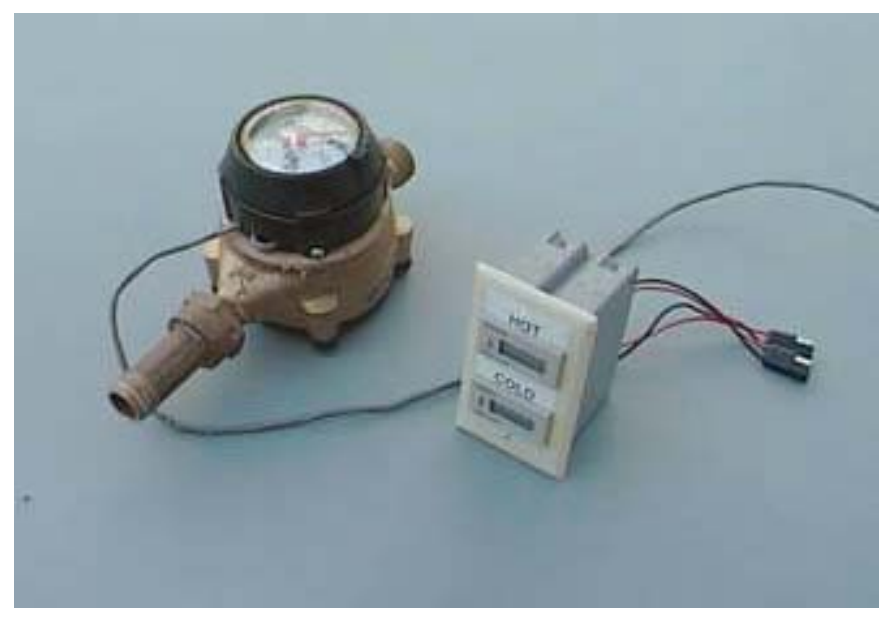

Water consumption of clothes washers in the BWS Study was determined with conventional nutating disk water meters of the type used by many water utilities for determining a customer's water consumption. Water passing through this meter causes a disk within the meter itself to nutate or wobble about a fixed axis with a frequency which is proportional to the volume flow rate of water through the meter. The nutating disk is affixed to a 4-pole permanent magnet, so that as water passes through the meter, the magnet rotates and a register on the face of the meter itself senses its rotation. We removed (temporarily) the register (as shown at the photo at the right) and installed a small reed switch on the body of the meter itself. The magnet hidden inside the bronze casing caused the reed switch to open and close four times with each nutation. Knowledge of the number of nutations per gallon of water passing through the meter (provided by the meter manufacturer) along with information concerning the four-pole magnet allowed us to develop the modified meter relationship between gallons of water passing through the meter and number of reed switch closures. For the meters chosen, 200 contact closures represented approximately one gallon of water through the meter. 
The reed switch was connected to a battery-powered electronic counter (Redington Eagle Electronic Counter, Model No. 5300-1000) as shown in the photo. Two counters, one for the hot and one for the cold water meters, were placed into a single box, and the box was placed in a convenient location in the laundry room of each participant. Participants had only to read the numerals on each electronic counter once with each laundry load, record the information on datasheets. No resetting was required, and the water consumption for each individual load could be determined from the datasheets submitted from successive loads.

\section{Dryer Energy Meter}

An energy meter was used to measure the electrical energy consumption ( $\mathrm{kWh}$ ) of the dryer throughout the experiment. The energy meter was Model ECM 1200 manufactured by Brultech, Ltd. Each participant read and recorded the $\mathrm{kWh}$ reading after each drying cycle, and the energy for an individual load was determined by differences in subsequent readings. The meter was originally designed for metering appliances that operate on 120 VAC; however electric dryers operate on 240 VAC. We modified the meter so that the power consumption of a dryer could be determined. The design described below is to help other experimenters facing a similar problem.

The normal energy meter (shown metering a conventional $120 \mathrm{VAC}$ refrigerator) determines electrical power by voltage and current measurements. In the hookup shown, the duplex outlet provides the same voltage to the refrigerator as to the $\mathrm{AC}$ adapter that

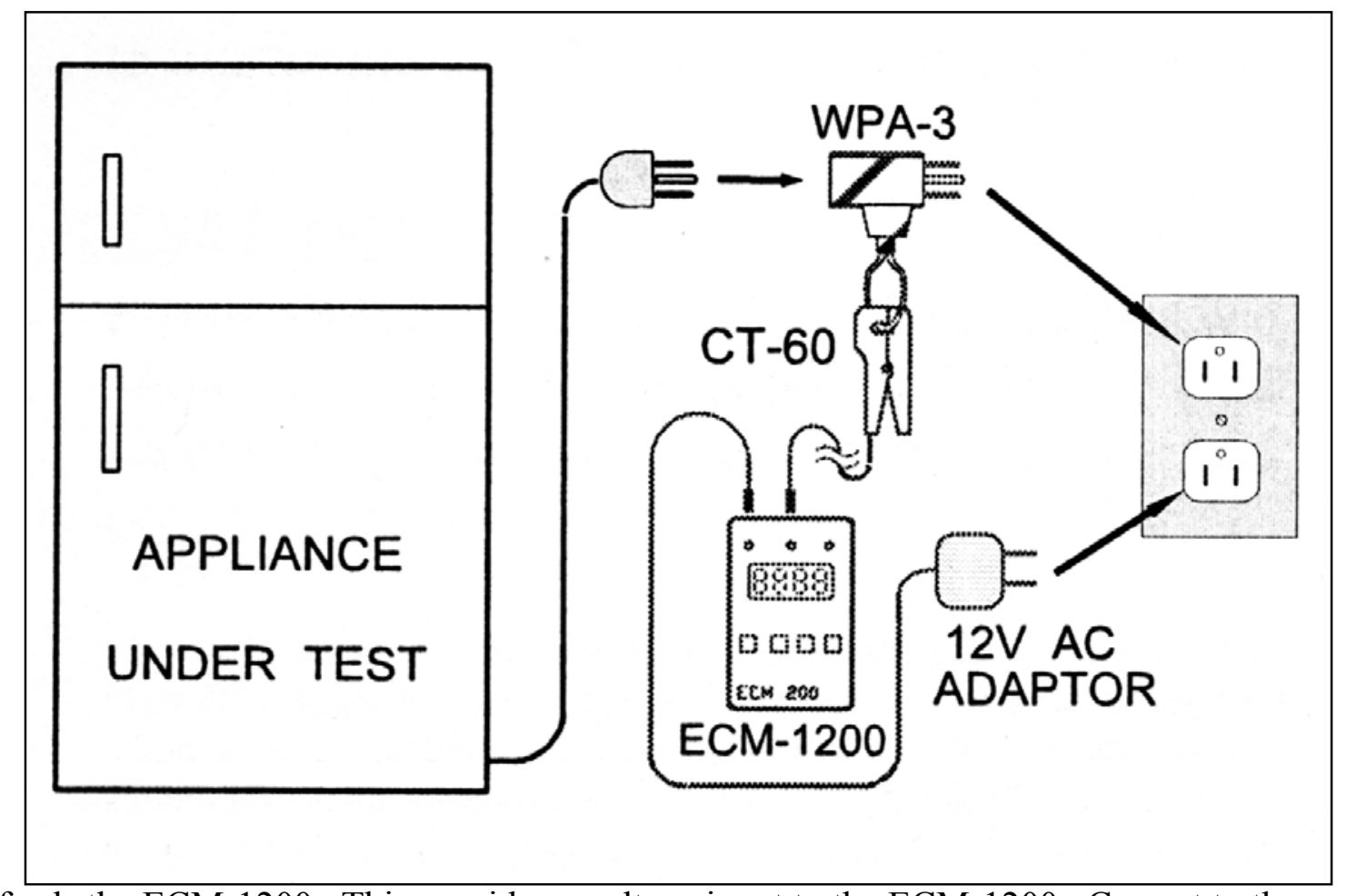

feeds the ECM-1200. This provides a voltage input to the ECM-1200. Current to the refrigerator is measured using a current transformer (CT-60); the ratio of current to the refrigerator and current to the EMC-1200 is fixed by the turns ratio in the CT. 
In a 240-VAC appliance (e.g. the electric dryer), there are two $120 \mathrm{VAC}$ legs (L1 and L2) with a neutral wire between them. To measure the power to a 240-VAC appliance, we needed to know the potential difference between one hot leg and neutral (approximately $120 \mathrm{VAC}$ ), and the current through both legs. We accomplished this using a single CT with both L1 and L2 passing through the CT core in such a way that the output of the CT would be additive. To accomplish this, we routed L1 through the CT core in one direction and L2 through in the opposite direction. As long as the 240-VAC is balanced (i.e. $120 \mathrm{VAC}$ on each side), the power for the 240 -VAC appliance will be measured. The design accommodates situations where the current through L1 and L2 are unequal such as could be the case where 120-VAC controls would be used on one side of the 240$\mathrm{VAC}$ and not on the other.

The pictures below show the components that were fabricated and used to employ a single CT. This enabled us to use the Brultech meter.
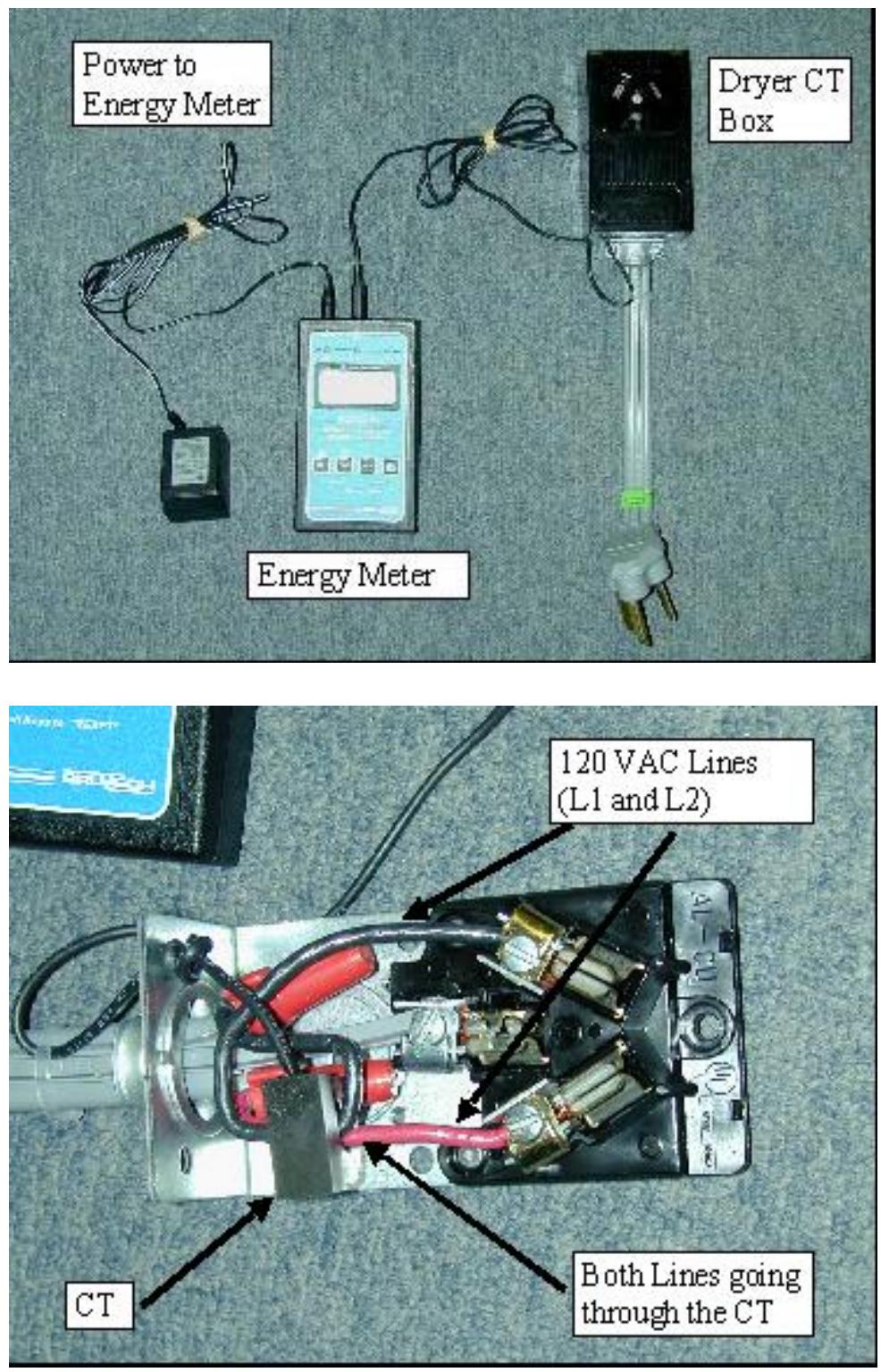



\section{APPENDIX B. REPORTS TO RESIDENTS}

Contents of Letter to Participants enclosed with Data Sheet comparison Report

\section{Dear Mr. Doe,}

We have completed the analysis of the data collected by you during the Boston Washer Study. The data collected was for a period of five months, half with your old machines and half with the new horizontal-axis machines. We greatly appreciate your participation and willingness to help during the study. We hope that this study provides a better understanding of the impact that high-efficiency washer can have on water and energy consumption in an urban setting.

Enclosed with this letter is an information sheet explaining the results we tabulated from your individual data along with overall findings of the study. You will see different categories listed down the first column with the corresponding data in the columns to the right. The information is broken down into phase I results (June - Mid August, 2000), phase II results (Mid August - Mid October, 2000), totals for both phases, and finally the overall savings from the project.

\section{Water Savings}

The first section details the number of gallons of hot, cold, and hot + cold water used by the washer for each phase of the study. In order to compare apples to apples, the savings are displayed in terms of water use per pound of laundry. It would not be fair to compare only the total gallons or the number of loads to determine the savings, because each participant washed a different number of loads in each phase, and their load weight averages were not the same for each phase. We also showed the average number of gallons of water used per load and the average number of gallons saved per load after the changeout.

\section{Number of Loads and Load Weights}

The number of loads and their weights are displayed in the next section. This shows the number of loads washed, average loads washed per week, total weight of the loads, average weight per load, along with the heaviest and lightest load. These numbers are also compared to the overall findings of the project.

\section{Energy Consumption}

The amount of energy consumed (kWh) per pound of laundry is given, along with the savings for both the washer and dryer. Your individual averages are given and you can compare your results with averages for the study. Again, the energy consumption is normalized to load weight so that comparisons can be made.

\section{Detergent Use}

The amount of detergent (cups) used per pound of laundry is given so that you can compare consumption patterns between phases of the study. 
There are cases where the study averages will not reflect your individual results. This does not mean you did anything wrong or the machine failed to operate as designed. Differences can often be explained by a difference in your personal laundry habits and patterns such as:

- Different amounts of detergent

- Different size loads and types of clothing

- Different wash and rinse settings

- Different dryer settings (timed-dry to auto-dry)

We have found that small changes in one area can lead to different results.

The study was a great success, which can be seen by the $50 \%$ washer energy savings, $22 \%$ dryer energy savings, $41 \%$ water savings, and $20 \%$ detergent savings. There was also a significant improvement in the overall satisfaction with cleanliness and dampness of the clothing after wash. We want to thank you for your participation in the study, for without your perseverance and diligence, the study could not have been done.

Sincerely,

David Durfee and John Tomlinson

Enclosure 


\section{APPENDIX C. INTEGRITY AND QUALITY OF DATA}

The overall completeness of the data received from participants was very good with and average completion rate of $95 \%$ for phase I and $96 \%$ for phase II. These percentages mean that only $4 \%$ to $5 \%$ of the time a field was left blank and was recorded as NA (not available) in the analysis. The quality of the data was also good with suspected outliers automatically checked and corrected by the analysis program. There were opportunities for mistakes to be made in the data collection by the participants such as: recording data incorrectly, weighing loads incorrectly, energy meter resetting or placed on the wrong setting, water meters not working properly, and others. These problems were recognized and corrected during the analysis through automatic and visual inspection.

\section{Completeness of the Recorded Data}

Part of the quality of the data is the completeness of the data records. The completeness of each data sheet or record refers to the number of nonblank entries in each data field when compared to the total number of data records that were turned in. When a data sheet was received and an entry was left blank, the field was entered as NA in the data spreadsheets. These NA's were counted for each of the 14 fields the participants were required to enter. The lowest field completion rate was $86 \%$ in phase I category of Satisfaction of Dampness. All other fields had a completion rate of $90 \%$ or higher with a $100 \%$ completion rate in phase II Date field. The individual categories can be seen in the table below.

Table 3. Completeness of Phase I and II Data Records

\begin{tabular}{|l|r|r|}
\hline Data Fields & \multicolumn{1}{|c|}{ Phase I } & \multicolumn{1}{c|}{ Phase II } \\
\hline Total Number of Records/Percentage & Percentage & Percentage \\
\hline Date & $97 \%$ & $100 \%$ \\
\hline Time & $99 \%$ & $98 \%$ \\
\hline Detergent Amount & $98 \%$ & $97 \%$ \\
\hline Load Size & $97 \%$ & $93 \%$ \\
\hline Wash Temperature & $98 \%$ & $97 \%$ \\
\hline Rinse Temperature & $97 \%$ & $97 \%$ \\
\hline Load Weight After Wash & $95 \%$ & $96 \%$ \\
\hline Cold Water Reading & $98 \%$ & $98 \%$ \\
\hline Hot Water Reading & $96 \%$ & $96 \%$ \\
\hline Satisfaction with Dampness After Wash & $86 \%$ & $91 \%$ \\
\hline Load Weight after Dry & $93 \%$ & $95 \%$ \\
\hline Energy Reading & $91 \%$ & $95 \%$ \\
\hline Satisfaction with Cleanliness After Dry & $91 \%$ & $93 \%$ \\
\hline
\end{tabular}

\section{Integrity of Data}

The second area of data quality is the accuracy of the recorded readings and the various calculations from the recorded readings in each data record. There were a few values that 
were recorded incorrectly by the participants on occasion and calculations which seemed incorrect or out of range. These possible mistakes and remedies are described in the following table.

Table 4. Problems and Remedies

\begin{tabular}{|l|l|}
\hline \multicolumn{1}{|c|}{ Problem/Error } & \multicolumn{1}{c|}{ Remedy } \\
\hline $\begin{array}{l}\text { Numbers recorded incorrectly (numbers } \\
\text { switched or left out) }\end{array}$ & $\begin{array}{l}\text { All the data was scanned automatically to } \\
\text { check if it was in a reasonable range }\end{array}$ \\
\hline $\begin{array}{l}\text { Scale displayed weight without including } \\
\text { basket }\end{array}$ & $\begin{array}{l}\text { A check was done to see if the weight was } \\
\text { too low or high, if it was, the error was } \\
\text { fixed automatically }\end{array}$ \\
\hline Water meter stopped working & $\begin{array}{l}\text { Visual inspection of cumulative charts } \\
\text { would signal the problem, and the meter } \\
\text { was quickly fixed with analysis } \\
\text { compensation given }\end{array}$ \\
\hline $\begin{array}{l}\text { Energy meter on the wrong setting or reset } \\
\text { to zero }\end{array}$ & $\begin{array}{l}\text { Automatic checks and visual inspection } \\
\text { detected these errors and the meter was } \\
\text { fixed with special attention taken during } \\
\text { the analysis to compensate for the error }\end{array}$ \\
\hline Entire laundry loads were not recorded & $\begin{array}{l}\text { Cumulative water and energy charting } \\
\text { displayed the missing loads and special } \\
\text { attention during analysis accounted for the } \\
\text { absence of data }\end{array}$ \\
\hline $\begin{array}{l}\text { Calculation errors during analysis or out of } \\
\text { range answers }\end{array}$ & $\begin{array}{l}\text { Automatic checks scanned all calculations } \\
\text { for out of range answers, each instance was } \\
\text { specifically handled and corrected if } \\
\text { necessary }\end{array}$ \\
\hline
\end{tabular}

The quality and integrity of the data was given the highest priority to ensure valid results and conclusions were obtained. 


\section{APPENDIX D. INDIVIDUAL WATER TAP TEMPERATURES}

The water temperatures of both the hot and cold water at each participant's washer were measured at the beginning of and midway through the study. The individual water temperatures and their differences are provided in Table 5. The average hot, cold, and water temperature differences were found to be $144.6,58.8$, and $85.8^{\circ} \mathrm{F}$, respectively.

Table 5. Measured Hot and Cold Water Temperatures

\begin{tabular}{|c|c|c|c|}
\hline Participant & Hot Water Temp ${ }^{\circ} \mathrm{F}$ & Cold Water Temp ${ }^{\circ} \mathrm{F}$ & Difference ${ }^{\circ} \mathrm{F}$ \\
\hline 1 & 140.3 & 59.4 & 80.9 \\
\hline 2 & 145 & 58 & 87 \\
\hline 3 & 145 & 56.7 & 88.3 \\
\hline 4 & 146.4 & 57.5 & 88.9 \\
\hline 5 & 143.8 & 57.4 & 86.4 \\
\hline 6 & 145.6 & 59.1 & 86.5 \\
\hline 7 & 151 & 55.5 & 95.5 \\
\hline 8 & 142.7 & 58.6 & 84.1 \\
\hline 9 & 143 & 58.5 & 84.5 \\
\hline 10 & 144.9 & 58.6 & 86.3 \\
\hline 11 & 145 & 57.5 & 87.5 \\
\hline 12 & 143.9 & 57.1 & 86.8 \\
\hline 13 & 144.7 & 58 & 86.7 \\
\hline 14 & 147 & 57 & 90 \\
\hline 15 & 142.5 & 59.3 & 83.2 \\
\hline 16 & 148.4 & 56.1 & 92.3 \\
\hline 17 & 142.5 & 62.7 & 79.8 \\
\hline 18 & 143 & 57.6 & 85.4 \\
\hline 19 & 135.7 & 71.4 & 64.3 \\
\hline 20 & 144.8 & 56.8 & 88 \\
\hline 21 & 144.1 & 59.3 & 84.8 \\
\hline 22 & 142 & 58 & 84 \\
\hline 23 & 144 & 60.5 & 83.5 \\
\hline 24 & 140.5 & 61.4 & 79.1 \\
\hline 25 & 149.9 & 57.1 & 92.8 \\
\hline 26 & 144.5 & 60.5 & 84 \\
\hline 27 & 142.5 & 58 & 84.5 \\
\hline 28 & 142 & 57.7 & 84.3 \\
\hline 29 & 148.7 & 57.4 & 91.3 \\
\hline 30 & 144.8 & 57 & 87.8 \\
\hline 31 & 146.7 & 57.9 & 88.8 \\
\hline 32 & 147 & 57.3 & 89.7 \\
\hline 33 & 146 & 57.9 & 88.1 \\
\hline 34 & 146.4 & 56.6 & 89.8 \\
\hline 35 & 146.3 & 57.7 & 88.6 \\
\hline
\end{tabular}




\begin{tabular}{|l|r|r|r|}
\hline 36 & 146.2 & 57.9 & 88.3 \\
\hline 37 & 147 & 59.5 & 87.5 \\
\hline 38 & 144 & 57 & 87 \\
\hline 39 & 144.1 & 57.7 & 86.4 \\
\hline 40 & 140.7 & 58.4 & 82.3 \\
\hline 41 & 142.7 & 58.7 & 84 \\
\hline 42 & 148.7 & 56.5 & 92.2 \\
\hline 43 & 158 & 68 & 90 \\
\hline 44 & 138.1 & 59.6 & 78.5 \\
\hline 45 & 142.7 & 58.3 & 84.4 \\
\hline 46 & 147.6 & 56.3 & 91.3 \\
\hline 47 & 140 & 65 & 75 \\
\hline 48 & 145.5 & 57.4 & 88.1 \\
\hline 49 & 140.8 & 59.9 & 80.9 \\
\hline 50 & 142.2 & 60.9 & 81.3 \\
\hline
\end{tabular}

